\title{
Approaching towards sustainable supply chain under the spotlight of business intelligence
}

\author{
Mohammad Reza Seddigh $^{1} \cdot$ Sajjad Shokouhyar $^{1}$ (D) Fatemeh Loghmani $^{1}$
}

Accepted: 20 December 2021

(c) The Author(s), under exclusive licence to Springer Science+Business Media, LLC, part of Springer Nature 2022

\begin{abstract}
These two main objectives of this study are to present a theoretical model to explain how business intelligence capabilities influence the company's supply chain sustainability and to examine the relationships among different BI and CSCS dimensions. This study was conducted with the use of a standard BI questionnaire along with the United Nations CSCS questionnaire among 234 Iranian pharmaceutical companies, from which 188 were also surveyed. Smart pls3 and partial least squares methods were used for validity as well as reliability evaluation of the measurement model. According to the findings, BI significantly affects the sustainability of the pharmaceutical supply chain and some of its dimensions, including vision, scope, and internal aspects, thereby the hypothesis indicating the effect of BI on these dimensions was accepted. However, there was an insignificantly positive relationship between BI and the other dimensions of CSCS, including expectation, engagement, and goals; hence, the hypothesis indicating the effect of BI on these dimensions was rejected. If the policy of the board is to implement supply chain sustainability, BI can have a greater impact on the company. Otherwise, BI may be implemented with not much effect though it can be indirectly beneficial to these companies. No studies have been performed on direct examination of the relationship of BI and CSCS and their various dimensions with the use of an extensive survey among Iran's pharmaceutical companies. Also, this study reveals some facts about the sustainability of the pharmaceutical supply chain, BI, and relevant issues as significant obstacles against a sustainable supply chain and BI. This article also supports the UN questionnaire on supply chain sustainability and adopts it in the surveys. Furthermore, various social networks such as Facebook, Twitter, and Instagram were compared, and it was concluded that the data required for the pharmaceutical industry was more accessible from Twitter, in comparison to the other social networks.
\end{abstract}

Keywords Sustainable development · Pharmaceutical supply chain · Business intelligence · The United Nations

\footnotetext{
Sajjad Shokouhyar

s_shokouhyar@sbu.ac.ir
}

Mohammad Reza Seddigh

mrseddigh@innovative.land

Fatemeh Loghmani

Fatemeh.loghmani.fl@gmail.com

1 Faculty of Management and Accounting, Shahid Beheshti University, Tehran, Iran 


\section{Introduction}

Nowadays, given the many socio-economic and environmental crises arising worldwide, some changes in business and economics seem to be necessary (Bhargava, 2020). According to Common future book by Brundtland (1987), sustainability is defined as the ability and power to meet individuals' needs in the future society without compromising the ability to meet the needs of today's society (Sutrisno et al., 2019) in the future, human beings will face many problems such as the shortage of natural resources. This issue has posed a global concern as such sustainable development has been a hotbed of debate and research among many scholars and international organizations (Shokouhyar et al., 2019). Many environmental problems, such as food waste, plastic pollution, deforestation, air pollution, agriculture, etc., have a high impact on society and the way people live.

Sustainable development can be defined as the process which leads to a favorable future for human communities where the conditions of life and employment of resources are consistent with human demands. Furthermore, access to these necessary resources increases the quality of human life (Yilmaz \& Tekin, 2018). Sustainable development offers solutions for the structural, societal as well as economic patterns of development aimed at dealing with problems including natural resources depletion, biological systems destruction, pollution, climate change, overwhelming population, inequality, and the diminishing quality of human beings' lives, and so on (Fulzele and Shankar, 2021).

The process of sustainable development must be consistent with the present and future needs in terms of resource utilization and investment direction, development of technology, and institutional change. More specifically, sustainable development seeks to address the following five basic needs: integrating conservation and development, supplying human's basic biological needs, achieving social justice, autonomy, and cultural diversity, and maintaining ecological unity (Tang \& Al Qahtani, 2019). Accordingly, the sustainable development goals document was pursued at the UN sustainable development summit in September in the United States (United Nations sustainable development summit, 2015).

The supply chain network is also one of the most important economic activities for businesses and competitive systems (Midya et al., 2020). If the supply chain is flexible, it can anticipate unpredictable events and it can adapt to new changes and factors and respond quicker (Katsaliaki et al., 2021). Supply chain sustainability management is to ensure the continuity of business and the long-term value of the companies ethically, socially, and environmentally (UN guideline, 2015).

The UN Global Compact (UNGC) and sustainable development goals operate under the auspices of the UN (Rasche, 2020). The UNGC is the most important and largest voluntary corporate initiative in the world, which refers to agreements encouraging the member firms to monitor social progress (Abdelzaher et al., 2019). The UNGC deteminse the fair share of supply chains in sustainable development and is committed to observing 10 principles such as protecting human rights, combating corruption, observing working conditions and standards, and accepting environmental responsibilities (Shoukouhyar and Seddigh, 2020; Abdelzaher et al., 2019). Accordingly, there is a need to focus on and research the UN global compact and more knowledge is required to understand how managers learn about their sustainability and responsibility (Rasche, 2020).

Business Intelligence (BI) has received a great deal of attention regarding the increased access to information via electronic tools and communication (Caseiro and Coelho, 2018). BI systems contribute significantly to performance improvement across organizations and supporting important decisions in organizations (Arefin et al., 2015). BI refers to the process 
of collecting and disseminating information that is necessary to make a strategic decision (Arefin et al., 2015). BI helps managers at high, medium, and low levels to use accurate and timely information and readily available information to make critical decisions (Elbashir et al., 2008; Arefin et al., 2015). If the information collected is too much or too less than the right amount, managers may make wrong decisions and create a situation of uncertainty about the decisions made, or it may delay the decision (Bag et al., 2020). BI has been the focus of many business communities over the past few decades (Shokouhyar et al., 2019).

Various articles have indirectly referred to the relationship between BI and various factors of sustainable development, which the questionnaire of the UN represents the same dimensions (Caseiro and Coelho, 2018; Liang \& Liu, 2018; Arnott et al., 2017). Past research has also shown that Big Data Analysis (BDA) has impacts on sustainable development, development and the relationship between BD and BI has been confirmed in several articles (Shokouhyar et al., 2019; Wang \& Kung, 2018).

With the improvement of BD, the introduction of a BI system and applications analyzing the data is now one of the most significant issues (Liang \& Liu, 2018).

Even though several studies have been performed on the various roles of BI, BD, sustainable development, and supply chain. There are few studies examining the BI effects on the supply chain sustainability. This study considers the pharmaceutical supply chain because health is the main part of each individual's life, and the pharmaceutical supply chain has a critical contribution in this regard. The present study aimed to investigate the impact of BI on the pharmaceutical supply chain and its dimensions. We assume BI, as a tool that has solved many problems, might be effective in solving the supply chain sustainability problems. Some articles talked about the supply chain sustainability problems as well as some benefits of BI. Moreover, BI in a company is costly for some managers, and its resulting loss is far greater than its profit. To justify them logically, it is necessary to examine the relationship between BI and supply chain sustainability (Stodder, 2015). Accordingly, the following major questions were formed for the present study:

RQ1 What affects BI in the pharmaceutical supply chain?

RQ2 Do BI capabilities affect the supply chain sustainability and its various dimensions in companies significantly and positively?

\section{Study background and review of literature}

\subsection{Business intelligence}

The BI Systems analyze and integrate information by gathering various information from different internal and external sectors and are a kind of decision support (Ereth \& Baars, 2020; Lennerholt \& Laere, 2019). Introduction of business intelligence goes back to 1989 when Howard Dresner defined it as an umbrella term to describe decision making methods that are rooted in relevant, accurate, and timely information.

Data is generated and then stored and analyzed to obtain accurate, quality and right information (Bag et al., 2020). Some of these data are uncertain and not accurate enough and must be carefully analyzed (Kropat et al., 2011). A majority of authors agree that the data generated by the BI system must possess features such as accuracy, i.e. the obtained information is accurate in terms of subject, access to meaning, easy access to information. Furthermore, completeness shows that the available information is sufficient and complete. Timely also 
indicates that the information is up to date for the job. The information must also be secure, implying that personal and confidential information is not disclosed (Ereth \& Baars, 2020). Today, companies have recognized the value of information and knowledge and have invested heavily in organizational systems and software such as customer relationship management and supply chain management (Rouhani et al., 2016). Organizations tend to have a large amount of data; however, such data may be of low quality in the organizations. In contrast, BI can provide a significant amount of important, necessary, and useful information in a timely and accurate manner; hence, these systems can improve decision-making operations (Yeoh and Popovic, 2016). It is argued that BI can be simultaneously a product and a process. In the former, it helps firms to predict the behavior of customers, competitors, and suppliers. Moreover, it is a process because it can provide the grounds to develop important and essential information that contributes to the success and survival of the organizations (Arefin et al., 2015). Various studies have shown that they are a key source for individuals to reach success in BI since they encourage organizations to improve their employees' skills to achieve better customer satisfaction and services (Arnott et al., 2017). BI is constantly undergoing technological and business changes. The current technological innovations in both data storage and data analysis are constantly changing the role of BI.

According to the literature, business intelligence is a powerful tool that has been considered to tackle many problems and achieve a competitive advantage over opponents. Thus, corporations must have plans to develop this capability.

\subsection{Sustainable development}

During the past two decades, sustainable development has been associated with the integration of socio-economic and environmental objectives into the supply chain process, thereby creating a factor effective in improving sustainability (Koberg \& Longoni, 2019). Environmental goals are to invest in projects like air pollution prevention and pollution control and social goals are factors such as human rights, equality, and practices (Koberg \& Longoni, 2019). Attention to sustainability is a growing issue, and the term sustainable development was first used by Barbara Ward in the Cocoak declaration on environment and development (Rodriguez and Svensson, 2018).

To produce sustainable products in the pharmaceutical supply chain, the need to highlight the characteristics of suppliers, raw materials, and resources is felt (Hussain et al., 2018). High demand for products and their consumption has put pressure on industrial production and consequently has had a negative impact on society and the environment. Industrial growth is a serious global threat to environmental sustainability and natural resources. Sustainable organizations can maximize their market value in the short, medium, as well as long terms through the management of knowledge, social, economic, and biological issues (Melles, 2019). The world commission on environment and development has introduced sustainable development as what does not compromise the capabilities of the next generations in addressing their demands and responding to current needs (Lu et al, 2018). Due to the laws and regulations and pressures imposed by customers, competitors, and legislators, the companies must integrate sustainability and supply chain operations to respond to the environment and society (Aliakbari Nouri et al., 2018). Reports have revealed that the company's social responsibility methods are effective in meeting the employees' needs rather than improving financial status as such is sustainable methods seem to be of the essence in each organization (Narayanan et al., 2018). Regarding sustainable development, stakeholders expect social and environmental responsibilities to be included in business operations (Lu et al., 2018). Sustainability 
is an opportunity for the supply chain to increase its economic, social, and environmental performance (Melles, 2019). The high significance of environmental sustainability has been acknowledged for better performance and better competitive advantages (Rodriguez and Svensson, 2018). Sustainability management in global supply chains remains a challenge, and pharmaceutical companies are under pressure and poor condition (Koberg \& Longoni, 2019).

Information processing for managers increases when there is a discontinuity in the organizations; therefore, this issue introduces uncertainty within the supply chain (Montiel et al., 2016). Also, the uncertainty of supply and demand volume due to market fluctuations and economic instability has led researchers to look at these problems in the supply chain (Mizgier et al., 2012). For example, these days, due to COVID-19 and disease spread, producing safe and effective drugs requires clinical trials which lasts long (Mirzai et al., 2018) and also the demand for products such as vaccines, drugs, masks and cleaning and disinfection products is relatively high. Therefore, the supply of products must meet the need to avoid any disruption and concern.

Based on the literature, supply chain sustainability remains a major issue in the world. This problem is even more serious in pharmaceutical supply chains since it is highly influenced by local law and order. Therefore, urgent attention is required to deal with this issue, especially after the Coronavirus pandemic.

\section{3 $\mathrm{BI}$ and sustainable development}

Nowadays, with a lot of data being produced daily, the BI analysis has become the main tool for data mining and analysis (Saura \& Bennett, 2019). BI has a great impact on the agility of organizations so that a company can discover opportunities and minimize threats by absorbing diverse information (Cheng et al., 2020).

Since sustainable development is an important issue, and the BI analysis has been extremely helpful in various studies, researchers have spared their efforts to show how much $\mathrm{BI}$ increases sustainability. The concept of sustainability in the business allows businesses to be performed in a way not to jeopardize future needs and to make progress in the economy possible at the same time (Sutrisno et al., 2019).

Some articles gave the hint of the relationship between BI and sustainability (Caseiro \& Coelho, 2018; Liang \& Liu, 2018; Arnott et al., 2017). Various studies have referred to the firm sustainability as a business process offering long-term value to shareholders through seizing the situation and controlling the potential of environmental, social, and economic changes. It is possible to measure stable performance with the support provided by the BI system. Given the challenges resulted from the sustainability projects, it is possible to monitor the projects over the period of their execution using the BI approach. Some studies have argued that a company's BI system has a sustainability dimension. Sustainability data are a part of the enterprise data because of the integration of the sustainability data and corporate data models (Muntean, 2018).

Over the past few years, BD has become one of the key elements of BI. Many companies are now using BD to improve decision making and optimization. The BD process and BI analytics are powerful sources of support for decisions to be made based on BD, as a key part of BI (Liang \& Liu, 2018). Previous studies have revealed that BD affects the environmental, social as well as economic performance of the supply chain significantly (Amirmokhtar and Shokouhyar et al., 2021; Jeble \& Dubey, 2017; Shokouhyar et al., 2019). It has also been argued that the proper use of BD improves the supply chain even though it may have some 
shortcomings (Shokouhyar et al., 2019). It is also stated that BD plays an important role in enhancing business value and earning profits by BI and data analysis (Liang \& Liu, 2018). It can thus be inferred that BI also has impacts on sustainable development and is a useful factor contributing to sustainable development. In this regard, some articles have indirectly referred to this relationship, stating that BI might be conceptually related to the sustainability of supply chains (Caseiro \& Coelho, 2018; Liang \& Liu, 2018; Arnott et al., 2017).

Since BI has been proved to be a strong tool, using sophisticated methods of analysis and effective and logical decision-making systems, this question comes to mind that " Can BI be a solution to the problem of pharmaceutical supply chain sustainability?". If the answer is Yes, we have to demine valid formats of deploying BI systems throughout the drug supply chain.

\section{Research gap}

There are no studies, particularly associated with pharmaceutical supply chains, directly addressing the relationship between BI and supply chain sustainability and BI effects on sustainability. According to previous research, examining BI and supply chain sustainability is essential, especially in developing countries, and the existing research plays an important role in public health (Shokouhyar et al., 2019; Stodder, 2015). These are issues disregarded in the literature. Considering the UN questionnaire with regard to BI, there is no study on the development of the regional BI; however, BI has its own rules and culture in each country and region, and the BI context in any country and region must be consistent with the same country and region. The articles addressing the need for BI and supply chain sustainability emphasize that BI is a powerful tool for solving many problems in organizations and supply chains. On the other hand, supply chain sustainability is a problem that, if ignored, can cause further problems. On the other hand, there is a high possibility that BI can also be effective in providing the sustainability of supply chains (Stodder, 2015).

According to a detailed review of relevant articles, few studies have examined the impact of BI capabilities on various social, economic, and environmental sustainability aspects, especially considering the developing countries.

According to the literature, BI is a strong tool that has been so constructive in businesses, and the pharmaceutical supply chain faces serious problems in terms of sustainability.

We can understand that there might be a relation between BI and sustainability, even though there is no such study so far.

Now it is up to us to pay close attention to this subject and conduct research to determine how significant can BI help a sustainable pharmaceutical supply chain.

\section{Development of hypotheses and the research model}

Based upon the recommendation of Wamba and Gunasekaran (2017), Dubey et al. (2020) and Samar Ali et al. (2020), we explain the different parts of research model, and also the theoretical background.

\subsection{Business intelligence}

For making timely decisions about various corporate matters, decision makers need proper education on the social, economic, and environmental facts. Managers need to be able to 
gather information at the right time and analyze it using their BI systems to provide a higher quality of information for decision makers.

The model presented in this article illustrated the association of BI and supply chain sustainability and the impact of BI on sustainability. This model was developed based on the UN questionnaire and other standard papers (Peters et al., 2016; Mithas et al., 2011; Chapman \& Kihn, 2009; Wetzels et al., 2009; Dodson et al., 2008; UN Global Compact, 2018). BI collects sales and business data about the aspects such as factors driving customer satisfaction or competitors' strategies to analyze and classify the data and convert them into useful information to be further available to the decision makers. BI has three branches (namely infrastructure integration, functionality, as well as self-service of BI) with several sub-branches. The infrastructure of BI highly depends on the structure of companies and the data warehouse is organized based upon factors such as the type of data and the quality of analytics system platforms. This section consists of two sections: providing reports on BI infrastructure integration and preparing plans for BI infrastructure integration. BI functionality states how BI structures can be useful and practical for an organization and addresses BI reporting functionality and BI planning functionality, the first of which describes the power of reporting and the extent to which managers can have access and learn about information and also indicates whether or not the system has a high response rate. BI planning functionality states that the BI system is an acceptable model for business decisions and shows whether or not the collected data is updated in a timely manner. BI self-service describes how quickly and how often mid-level and senior managers reach and analyze BI. Because of a growing demand for data and analysis, the use of BI self-service is suggested. however, the operation of a BI self-service system is not simple. Sufficient information is needed for the performance of this system (Lennerholt \& Laere, 2019). BI self-service consists of two parts: management reporting and analysis systems and planning budgeting and forecasting systems.

\subsection{Sustainable supply chain in the framework of the United Nations}

The United Nations defines the supply chain sustainability goals so that the companies can better understand the concept of sustainable development and describe the environmental, economic, and social impacts of supply chains (UN global compact, 2018). The sustainable development goals emphasize the need for private business partnerships and create creativity in creating values such as poverty alleviation, complete elimination of hunger as well as environmental protection (Johannes et al., 2019).

The UN supply chain sustainability questionnaire consists of six components: Vision (i.e., organization's vision and attitude towards sustainable development), Expectation (i.e., the company's expectations of what it will achieve), Scope (i.e., the scope of business for the company), Engagement (i.e., how the company is related to the other companies), Internal (i.e., the extent of cooperation and communication in a company), and Goals (i.e., the specified goals of a company). In the academic context, various dimensions of supply chain sustainability have been examined, and it is sometimes believed that a comprehensive view of sustainability is needed. Others note that the supply chain approach refers to information sharing or access (Christopher \& Lee, 2004). 


\subsection{Theoretical background}

Following some research and consultation with experts, we came to a theoretical lens in the following two ways, assuming that BI affects the sustainability of the supply chain.

\subsubsection{Relationship between BDA and supply chain sustainability}

Previous studies have revealed that BD might have a significant relationship with BI. As the data grows and becomes more complicated in this time period, the need for BI systems along with proper and accurate analyses is more highlighted (Liang \& Liu, 2018). Since BDA has a significant effect on the supply chain sustainability (Shokouhyar et al., 2019; Wang \& Kung, 2018), and there is a strong relation between BDA and BI, the relationship between BI and supply chain sustainability is also likely as well.

\subsubsection{Previous works on the relationship between BI and sustainable supply chain}

Many academic papers have provided the clue, indicating that BI might affect the dimensions of sustainability in a supply chain. Some articles found a relationship between BI and vision. It has been argued that BI has a positive and direct impact on the success of an organization's organizational resources (Caseiro \& Coelho, 2018). Other articles have suggested the relationship between $\mathrm{BI}$ and expectations and argued that BI plays a significant role in making the organization act more intelligently and adopt better decisions using timely information (Liang $\&$ Liu, 2018). The relationship between BI and internal is also mentioned in some articles. Moreover, serious management support seems to be the most important factor affecting the success of BI (Arnott et al., 2017). The possible relationship between BI and scope is found out in some articles, indicating that BI systems can determine status and goals and cover a range of expectations and performance (Liang \& Liu, 2018). Furthermore, the relationship between $\mathrm{BI}$ and engagement is shown in some papers. The companies can establish business data collection links with other companies before competing in the markets (Arnott et al., 2017). Finally, the relationship between BI and the goal is also documented (Liang \& Liu, 2018). Accordingly, the following primary hypothesis has been raised in the present paper:

H1 BI capabilities affect organizations' supply chain sustainability positively and significantly.

BI provides the required condition for improving an organization's performance. A study showed that BI could be used to improve company performance or reduce unintended target customers (Liang \& Liu, 2018). The skills of teams in organizations have a great impact on the successful implementation of BI and can influence productivity and facilitate making the right decisions using quality information (Arnott et al., 2017; Liang \& Liu, 2018). According to the provided theoretical foundations, the other research hypotheses were formulated as follows:

H1(a) BI capabilities affect the vision and objectives of supply chain sustainability (vision) positively and significantly.

H1(b) BI capabilities affect the establishment of supply chain expectations and requirements (expectation) positively and significantly.

H1(c) BI capabilities affect engagement with suppliers and other businesses in the supply chain (engagement) positively and significantly. 


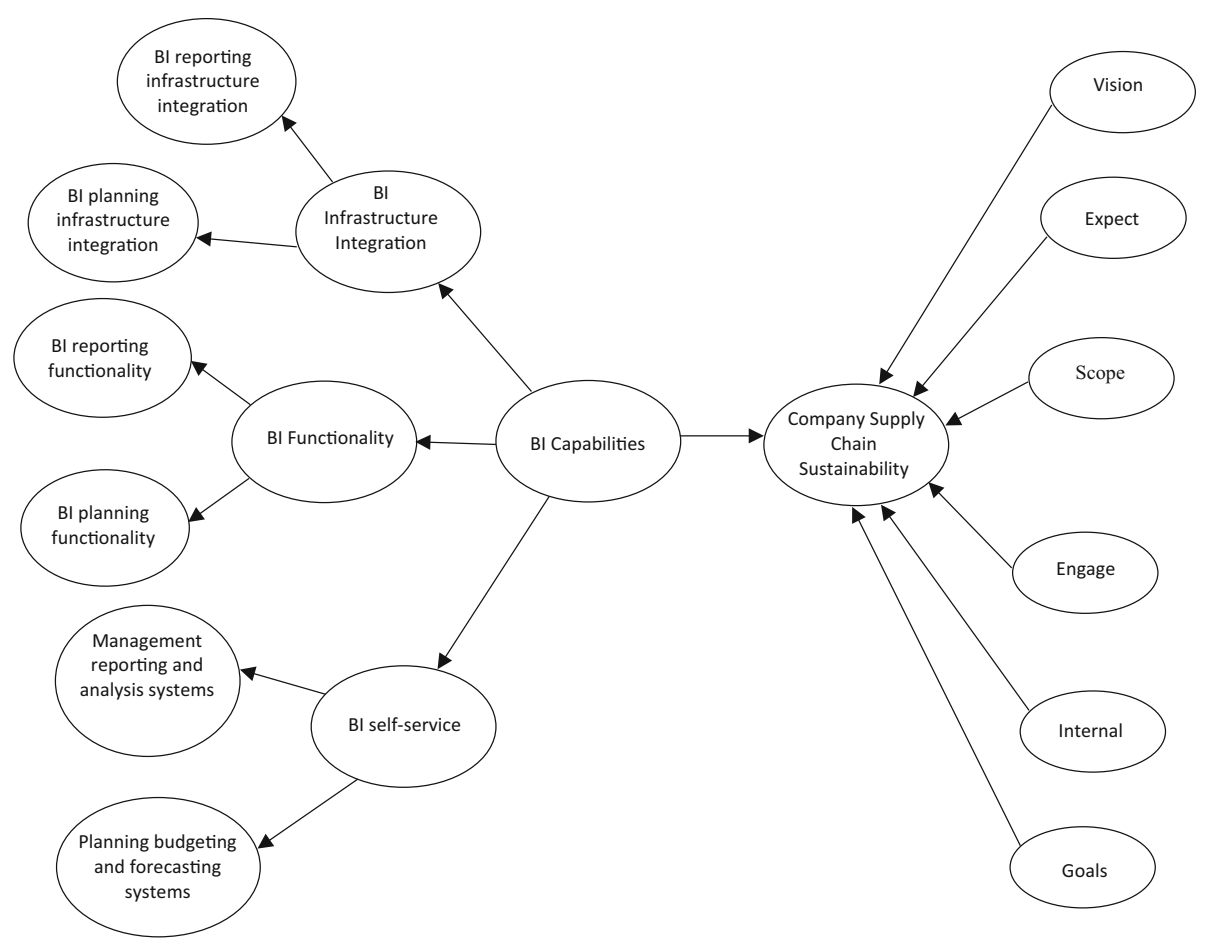

Fig. 1 Conceptual model

Some scholars argue that the primary purpose of a BI project is to use information as such the BI system focuses on converting the data into useful information and providing accurate information in a timely manner (Liang \& Liu, 2018). According to previous research, the presence of users in the BI system can be effective in their long-term operation (Arnott et al., 2017).

Some scholars define BI as the ability to provide information to businesses. BI focuses on analyzing data and converting them into efficient information to make the right decisions (Liang \& Liu, 2018). From this perspective, the following hypotheses were formed:

H1(d) BI capabilities affect determining the scope of activities (scope) positively and significantly.

H1(e) BI capabilities affect the assignment of internal roles and responsibilities (internal) positively and significantly.

H1(f) BI capabilities affect the creation of goals as well as tracking and communicating performance (goals) positively and significantly (Fig. 1).

\section{Research methodology}

Regarding BI sustainability and supply chain sustainability criteria, a standard questionnaire was developed according to the BI standard questionnaire and the United Nations' online 
Table 1 Demographics of respondents

\begin{tabular}{llc}
\hline Demographic variables & Level & $\begin{array}{l}\text { Frequency } \\
(\%)\end{array}$ \\
\hline \multirow{2}{*}{ Gender } & Male & 74 \\
& Female & 26 \\
Educational background & Information Technology & 14 \\
& Pharmacy (Pharm.D) & 61 \\
& Pharmacy (Ph.D) & 6 \\
& Economics & 16 \\
Position & Law & 3 \\
Age & Chief manager & 100 \\
& 25-35 & 11 \\
& $36-45$ & 46 \\
& Above 46 & 43
\end{tabular}

self-assessment of the supply chain maturity model. Pre-tests of the questionnaire were implemented using a standard deviation of 1.27. Accordingly, the questionnaires were submitted to 50 managers, who were specialists in the pharmaceutical supply chain (10 pharmacists in suppliers, 18 pharmacists in manufacturers, and 22 pharmacists in distribution entities). This questionnaire has been fully endorsed by the Expert panel of Iran's pharmaceutical supply chain. According to literature in statistics, formulas are presented in this paper (Bhattacharyya \& Richard, 2010; Ross, 2004; Wonnacott \& Wonnacott, 1990).

A standard deviation measures the dispersion of a dataset relative to its mean. The standard deviation is calculated as the square root of variance by determining each data point's deviation relative to the mean. If the data points are further from the mean, there is a higher deviation within the data set; thus, the more spread out the data, the higher the standard deviation.

\subsection{Collection of research data}

Regarding the limited size of the statistical population of the study (with only 512 senior managers in the Iranian pharmaceutical supply chain), the sample size was estimated to be 396 according to the statistical formula and the confidence level of $95 \%$. The questionnaire was sent via email to 512 managers and general managers of Iranian 234 pharmaceutical companies. The present project was a case study in Iranian since the data were gathered exclusively from Iranian pharmaceutical businesses.

It was expected from the respondents to send a copy of the results of the UN selfassessment. After the accountability deadline, as Baruch and Holtom (2008) suggested, managers who had not submitted their responses received emails were, prompting them to provide responses to the questionnaire as early as they could. Following several months of regular follow-ups, a number of 437 questionnaires could be obtained, which indicated an 85.35 percent response rate. Following the elimination of 29 defective questionnaires, 408 questionnaires from 188 companies were considered to be correct and applicable (Tables 1 and 2). The Cochran formula to calculate the sample size is given by: 
Table 2 Companies' properties

\begin{tabular}{llc}
\hline Companies' properties & Level & $\begin{array}{l}\text { Frequency } \\
(\%)\end{array}$ \\
\hline Position in supply chain & Supplier & 3.2 \\
& Manufacturer & 27.7 \\
& Importer & 55.9 \\
& Distributer & 13.2 \\
Structure & Government-own & 7.4 \\
& corporation & \\
& Privately held company & 67.9 \\
& Public company & 24.7 \\
Size & $10-249$ personnel & 82.9 \\
& 250-4999 & 16.9 \\
& 5000 or more & 0.2 \\
\hline
\end{tabular}

$$
\begin{aligned}
n & =\frac{N z^{2} \alpha / 2^{s^{2}}}{d^{2}(N-1)+z^{2} \alpha / 2^{s^{2}}}=\frac{512 \times 1.96^{2} \times 1.27}{0.06^{2}(511)+1.96^{2} \times 1.27} \\
& =\frac{3186.377}{1.839+6.22}=395.185 \cong 39
\end{aligned}
$$

Here, $\mathrm{n}$ refers to the sample size, $\mathrm{z}$ refers to the level of confidence according to the standard normal distribution (for a level of confidence of $95 \%, z=1.96$, for a level of confidence of $99 \%, z=2.575)$, $\mathrm{p}$ refers to the estimated proportion of the population that presents the characteristic (when unknown we use $p=0.5$ ) and d refers to the tolerated margin of error (for example we want to know the real proportion within 5\%).

\subsection{The format of the survey}

Regarding the Likert scale, the respondents were expected to demonstrate the ability of BI in their organizations using options at a range of 1 (complete disagreement) to 5 (complete agreement). Besides recording the economic, social, and environmental realities in the supply chain, the study sample was supposed to conduct a UN online evaluation of the medications, sharing the obtained results.

There were 41 questions in the questionnaire regarding BI capabilities which assessed the business entities' ability in addressing social, economic, and environmental issues with the use of BI. The other part of the questionnaire consists of the UN online self-assessment, which includes six key questions. The respondents have to respond to them based on the Likert scale system, ranging from 1 (no recent actions) to 5 (best practice). It should be noted that quantitative approaches were integrated with quantitative methods based on research frameworks proposed by Creswell (2003) to collect measurable data for surveys. In other words, the present project was performed quantitatively. 


\subsection{Avoiding bias}

For avoidance from biases, the respondents were ensured that their company's name was not needed for the study (Chong et al., 2011). The survey comprised two major sections. Implementation of Baruch and Holtom's (2008) wave analysis aimed at avoiding non-response bias. The responses of early and late waves of returned surveys were analyzed assuming that the responses of late respondents were indicative of the non-respondents' responses. As the results showed, there were no significant differences between early-wave and latewave groups from a statistical perspective, indicating that these were no concerns about non-response bias in the current study (Prajogo \& McDermott, 2011). Moreover, the tests were performed to identify if the main factors were responsible for a majority of the explained variance to find any potential common method biases (Podsakoff \& Organ, 1986). The correlation matrix (Table 3) showed the highest inter-construct correlation of 0.758 , whereas common method bias was typically reported for particularly high correlations ( $r>0.90$ ) (Bagozzi \& Yi, 1988). Accordingly, there were no concerns about the common method bias either.

\section{Analysis of collected data}

\subsection{Methods and tools for data analysis (discrete scale)}

In the current study, after conducting necessary studies and investigations, the research model was conceptualized, and the hypothesized relationships were validated with the use of partial least squares (PLS) and structural equation modeling (SEM).

According to a number of researchers (Dubey et al., 2020; Sarstedt et al., 2019; Hair et al., 2020), the PLS algorithm are suitable for this type of study since it allows the simultaneous estimation of structural models and the measurement of non-parametric assumptions and is a multivariate technique based on hidden and explicit variables. This research deployed partial least squares based structural equation modeling (PLS-SEM) as it estimates hierarchical models by removing the uncertainty of inadmissible solutions using its flexible assumptions and, in this study, the multivariate normality criterion is not met. (Hair et al., 2020; Wamba \& Gunasekaran, 2017). According to Kwong and Wong (2013) all the experiments were performed using Smart PLS 3. The positive of this software is its insensitivity to the normality of the collected data (Hair et al., 2020; Sarstedt et al., 2019). In addition, the developed model was evaluated using this software in the present study.

Based upon the work of (Hair et al., 2020; Wamba \& Gunasekaran, 2017; Dubey et al., 2020; Sarstedt et al., 2019; Samar Ali et al., 2020), the scale used in this essay was considered to be discrete we used the Likert scale test and used a large number of members that are acceptable based on statistical formulas (Hair et al., 2020; Wamba \& Gunasekaran, 2017; Dubey et al., 2020; Sarstedt et al., 2019; Samar Ali et al., 2020).

\subsection{Evaluating the structural model (robustness checks in PLS-SEM)}

We examined the measurement model, in several steps to make sure model is robust, valid and accurate. 





Table 4 The final results of seven hypotheses

\begin{tabular}{lllcl}
\hline Hypotheses direct effect & Path coefficient & STERR & Z statistic & Test result \\
\hline $\mathrm{BIC} \rightarrow$ Vision & 0.4073 & 0.0053 & $9.8674^{* *}$ & Accepted \\
$\mathrm{BIC} \rightarrow$ Expect & 0.0641 & 0.0631 & 1.7195 & Rejected \\
$\mathrm{BIC} \rightarrow$ Scope & 0.7423 & 0.091 & $86.3329^{* * *}$ & Accepted \\
$\mathrm{BIC} \rightarrow$ Engage & 0.1661 & 0.0063 & 1.4652 & Rejected \\
$\mathrm{BIC} \rightarrow$ Internal & 0.2167 & 0.05 & $4.5745^{* * *}$ & Accepted \\
$\mathrm{BIC} \rightarrow$ Goals & 0.0325 & 0.0392 & 0.5798 & Rejected \\
$\mathrm{BIC} \rightarrow$ CSCS & 0.9638 & 0.0042 & $193.8232^{* * *}$ & Accepted \\
\hline
\end{tabular}

\subsubsection{Lack of multicollinearity}

Estimation of the goodness of fit (GOF) was performed based on Tenenhaus, et al. (2005) for PLS path modeling, and it was found that the model was well-fitted as the value was > 0.36 (Wetzels et al., 2009). In the present work, GOF was 0.87 , showing a value of $>0.36$. Multicollinearity and collinearity diagnostics were also conducted for the constructs so that the structures forming CSCS could be evaluated. It was also found that the collinearity index (variance inflation factor) was VIF < 3 (Hair et al., 2020; Hair et al., 2006) which suggested that there were no concerns regarding multicollinearity in the present study.

$$
\mathrm{GOF}=\sqrt{\overline{\text { Communality }} \times \overline{R^{2}}} .
$$

Here, $R^{2}$ refers to coefficient of determination of the regression equation.

\subsubsection{Examining the significance of path coefficients}

BI capabilities affect goal creation along with tracking and communication of performance (goals) positively and significantly. According to the structural model, BI capabilities affect the company's supply chain sustainability positively and significantly, the path coefficients of accepted assumptions " BIC $\rightarrow$ Vision " (0.401), " BIC $\rightarrow$ Scope " (0.742), " BIC $\rightarrow$ Internal "(0.220), and the path " BIC $\rightarrow$ CSCS " with a path coefficient of 0.964 ( $p$-value $<0.001$ ), which explains $90.1 \%$ of the variance (Table 4). Therefore, based upon the work of (Hair et al., 2020; Wamba \& Gunasekaran, 2017; Sarstedt et al., 2019) there was strong support for the main hypothesis of the study given the significance of the path coefficient at $p<0.001$ and the path coefficients values are strong in predicting dependent (endogenous) constructs. Totally, the $\mathrm{R}^{2}$ scores for the main variable (BIC: $90.1 \%$ ) whose explanation was provided by the research model were considerably large in line with the effect sizes for $\mathrm{R}^{2}$ described by Cohen (1988) and Chin (2010) (Figs. 2 and 3).

\subsubsection{Validity and reliability}

Reliability and validity are examined in the measurement instrument analysis phase. If a structure has a high value of divergent validity, it then has a unique and specific conceptual orientation; however, the other structures do not. Confirmatory factor analysis (CFA) and Cronbach's alpha coefficient can be adopted to confirm the validity and reliability of the 


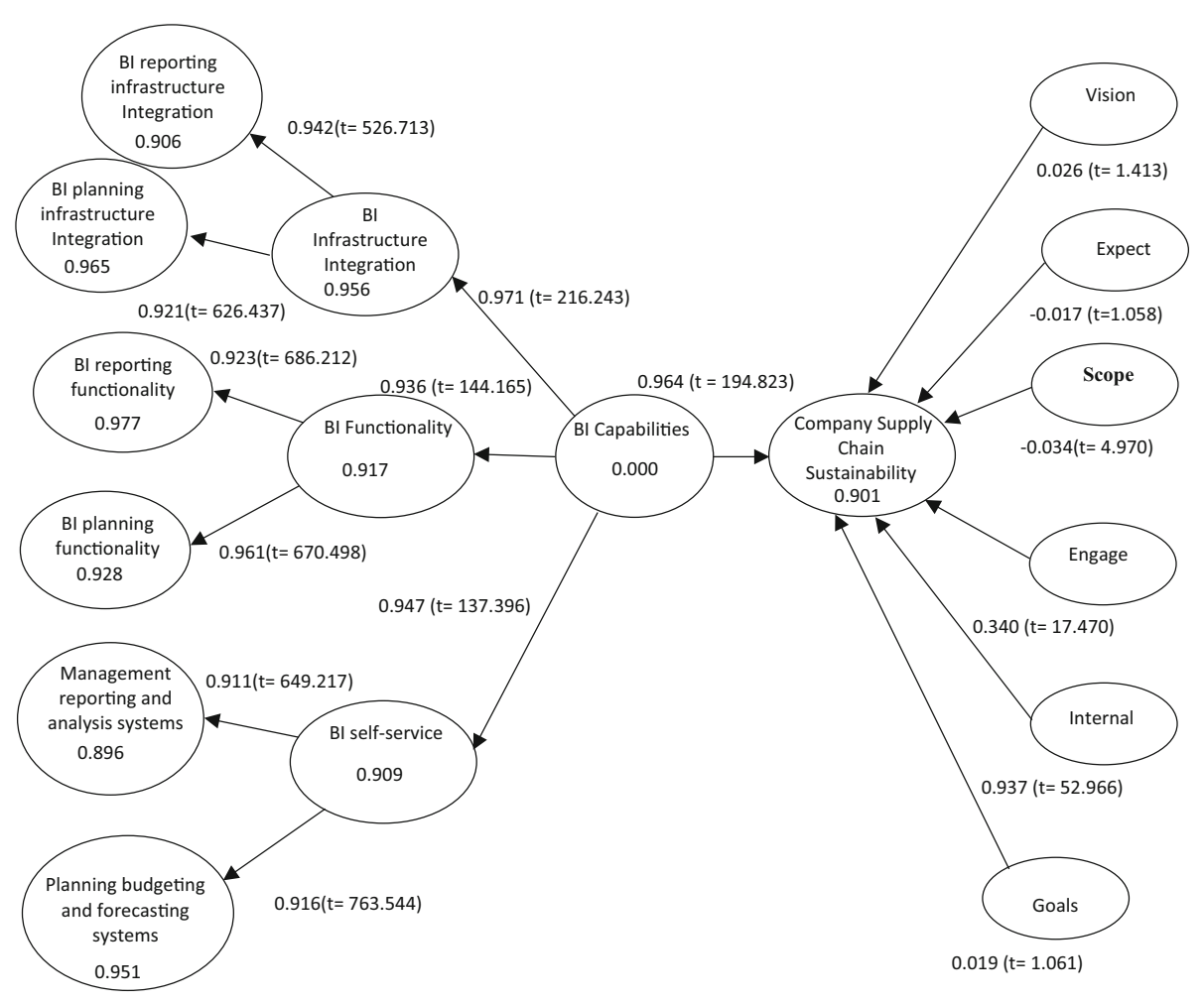

Fig. 2 Impact of BIC on CSCS (standard estimation and significance estimation)

conceptual model. In the present work, the reliability and validity of the research instruments were investigated and tested (Dubey et al., 2020). The reliability is calculated by using the following formulas:

$$
r_{1}=\frac{n}{n-1}\left(1-\frac{\sum p q}{S^{2}}\right), r_{2}=\frac{n}{n-1}\left(1-\frac{\bar{x}(n-\bar{x})}{n S^{2}}\right) .
$$

Here, $\mathrm{n}$ refers to the number of items on the instrument that measure that variable, $\mathrm{pq}$ refers to the variance of one item and $\mathrm{S}$ refers to the variance of the total score for the entire variable.

\subsubsection{Confirmatory factor analysis (CFA)}

This paper conducted CFA tests, convergent and divergent validity after detecting high and low loads on different factors. Table 5 shows the CFA results.

\subsubsection{Cronbach's alpha coefficient}

Calculation of Cronbach's alpha coefficient aimed at assessing the reliability of two parts of the questionnaire addressing BI and CSCS. According to Table 6, the higher the consistency among the questions is, the higher the Cronbach's alpha coefficient will be. And as the mean 


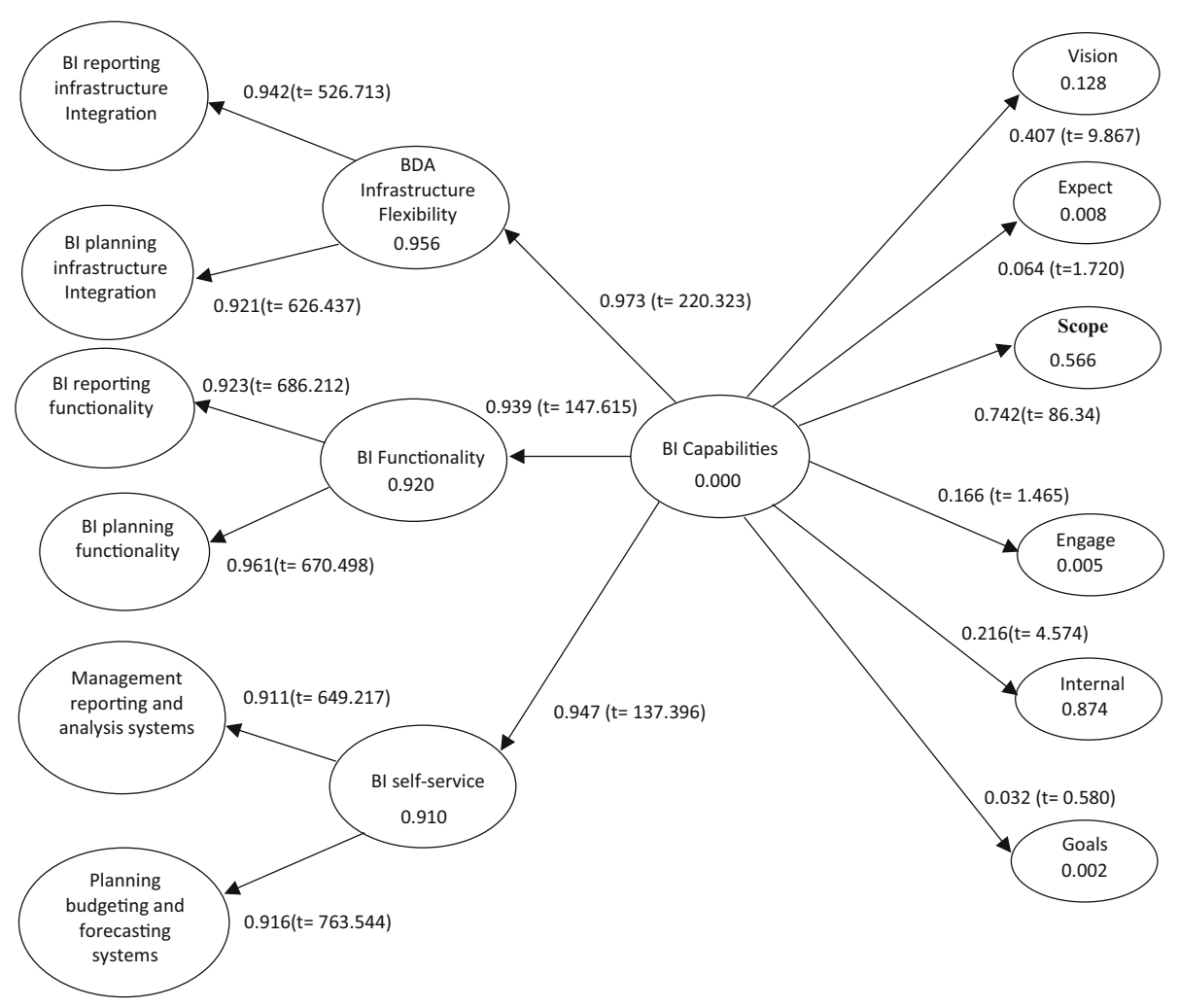

Fig. 3 Impact of BIC on different aspects of CSCS standard estimation and significance estimation

Table 5 Confirmatory factor analysis, AVE, Cronbach's alpha coefficient

\begin{tabular}{llllll}
\hline & Alpha & AVE & CR & Mean & SD \\
\hline Reporting infrastructure & 0.961 & 0.9121 & 0.9218 & 3.563 & 1.693 \\
Planning infrastructure & 0.969 & 0.9328 & 0.9543 & 3.268 & 1.234 \\
Reporting functionality & 0.956 & 0.9431 & 0.9420 & 2.236 & 1.980 \\
Planning functionality & 0.963 & 0.9152 & 0.9617 & 2.562 & 1.245 \\
Management reporting & 0.955 & 0.9323 & 0.9012 & 3.341 & 1.326 \\
Planning budgeting & 0.974 & 0.9137 & 0.9360 & 2.891 & 1.710 \\
\hline
\end{tabular}

variance of the questions increases, the Cronbach's alpha coefficient decreases. When the Cronbach's alpha coefficient is $>0.7$, the internal reliability is considered to be acceptable. Cronbach's alpha coefficient is calculated by using the following formula:

$$
a=\frac{k}{k-1}\left[1-\frac{\sum S_{i}^{2}}{S_{x}^{2}}\right] .
$$


Table 6 Standardized loadings of the latent constructs in the model $(* * * p<0.001)$

\begin{tabular}{|c|c|c|c|c|}
\hline $\begin{array}{l}\text { First-order } \\
\text { constructs }\end{array}$ & Indicators & Loadings & $\begin{array}{l}\text { Second-order } \\
\text { constructs and their } \\
\text { loadings }\end{array}$ & $\begin{array}{l}\text { Third-order construct } \\
\text { and loadings }\end{array}$ \\
\hline \multirow{4}{*}{$\begin{array}{l}\text { Reporting } \\
\text { infrastructure }\end{array}$} & RI 1 & $0.9651 * * *$ & \multirow{8}{*}{$\begin{array}{l}\text { Infrastructure } \\
\text { integration } \\
(0.75-0.95)\end{array}$} & \multirow{8}{*}{$\begin{array}{c}\text { BI capabilities } \\
(0.80-0.93)\end{array}$} \\
\hline & RI 2 & $0.9810 * * *$ & & \\
\hline & RI 3 & $0.9652 * * *$ & & \\
\hline & RI 4 & $0.9551 * * *$ & & \\
\hline \multirow{4}{*}{$\begin{array}{l}\text { Planning } \\
\text { infrastructure }\end{array}$} & PI 1 & $0.9561 * * *$ & & \\
\hline & PI 2 & $0.9631 * * *$ & & \\
\hline & PI 3 & $0.9701 * * *$ & & \\
\hline & PI 4 & $0.9781 * * *$ & & \\
\hline \multirow{4}{*}{$\begin{array}{l}\text { Reporting } \\
\text { functionality }\end{array}$} & RF1 & $0.9514 * * *$ & \multirow{8}{*}{$\begin{array}{r}\text { Functionality } \\
(0.95-0.98)\end{array}$} & \\
\hline & $\mathrm{RF} 2$ & $0.9617 * * *$ & & \\
\hline & RF3 & $0.9744 * * *$ & & \\
\hline & RF4 & $0.9623 * * *$ & & \\
\hline \multirow{4}{*}{$\begin{array}{l}\text { Planning } \\
\text { functionality }\end{array}$} & PF1 & $0.9554 * * *$ & & \\
\hline & $\mathrm{PF} 2$ & $0.9781 * * *$ & & \\
\hline & $\mathrm{PF} 3$ & $0.9781 * * *$ & & \\
\hline & PF4 & $0.9652 * * *$ & & \\
\hline \multirow{2}{*}{$\begin{array}{l}\text { Management } \\
\text { reporting }\end{array}$} & MR 1 & $0.9566^{* * *}$ & \multirow{4}{*}{$\begin{array}{l}\text { Self-service } \\
\quad(0.94-0.97)\end{array}$} & \\
\hline & MR 2 & $0.9641 * * *$ & & \\
\hline \multirow{2}{*}{$\begin{array}{l}\text { Planning } \\
\text { budgeting }\end{array}$} & PB1 & $0.9566^{* * *}$ & & \\
\hline & PB2 & $0.9562 * * *$ & & \\
\hline
\end{tabular}

Here, $\mathrm{k}$ refers to the number of scale items, $\mathrm{S}^{2}$ i refers to the variance associated with item I and $S^{2}{ }_{x}$ refers to the variance associated with the observed total scores.

\subsubsection{Standardized loadings of latent constructs}

In this paper, the BI capabilities model is a third-order model with three second-order structures and six first-order structures with 20 indices. According to the testing of convergence validity of the rest of the model, as shown in Table 6, the value of all operating loads is > 0.7, indicating that the convergent validity is accepted. According to Anderson and Gerbink (1988), convergent validity is loaded similarly to all the other variables on the detected hidden variables. CFA was used to evaluate the convergent validity of each construct. As presented in Table 6, the standard CFA loading confirms the convergent validity since the total loading was $>0.7$.

\subsubsection{Unidimensionality}

Using four criteria, we ensured that the measurement model was integrated. First, high internal stability (i.e., loadings N0.707, p b 0.01) for the concerned components supported integration. Second, integration was predicted by Cronbach's alpha value of $>0.7$ for all structures. 
Table 7 Criteria of AVE and CR

\begin{tabular}{lll}
\hline & AVE & Composite reliability \\
\hline Reporting infrastructure & 0.9233 & 0.9516 \\
Planning infrastructure & 0.9254 & 0.9652 \\
Reporting functionality & 0.9363 & 0.9426 \\
Planning functionality & 0.9526 & 0.9356 \\
Management reporting & 0.9325 & 0.9536 \\
Planning budgeting & 0.9452 & 0.9634 \\
\hline
\end{tabular}

Third, the AVE value of each construct was $>0.5$, which did not sufficiently indicate integration. The higher AVE indicates that the observed cases exhibit more variance than the error terms. Eventually, the composite reliability of a part with a cut-off value $>0.8$ could support integration.

\subsubsection{Correlation matrix and composite reliability}

The divergent validity was confirmed by calculating the square root of AVE in the correlation matrix diameter, as shown in Table 3. The results suggest that the AVE square root of a structure is more than its correlation with other structures and that the measurement model has an acceptable divergent validity. The outcomes show that the latent structures represent distinct concepts (Table 7).

The average variance extracted (AVE) can be calculated as follows:

$$
A V E=\frac{\sum\left(\lambda_{\mathrm{i}}^{2}\right)}{\sum\left(\lambda_{\mathrm{i}}^{2}\right)+\sum \text { vare }}
$$

Here, $\Lambda_{\mathrm{i}}$ refers to the factor loading of item $\mathrm{i}$ and $\operatorname{Var}(\mathrm{e})$ refers to the variance of the error of item $i$.

\subsubsection{Independence of Predictors}

The various tests we conducted in this essay, including "Unidimensionality", "Composite reliability", "Standard loadings", "Goodness of fit", and "VIF" demonstrate that the predictors in the model are independent (Hair et al., 2020; Wamba \& Gunasekaran, 2017; Dubey et al., 2020; Sarstedt et al., 2019; Samar Ali et al., 2020). The VIF can be calculated as follows:

$$
V I F=\frac{1}{1-R^{2}}
$$

Here, $R^{2}$ refers to coefficient of determination of the regression equation.

\section{Study results}

In the current paper, seven hypotheses were posed, the most important of which addressed the relationship between BI and CSCS and was confirmed. Moreover, it was aimed to measure the relationship among first order items (consisting of BI reporting infrastructure integration, BI planning infrastructure integration, BI reporting functionality, BI planning functionality, 
management reporting, and analysis systems, planning to budget, and information systems), second order items (BI infrastructure integration, BI functionality, and BI self-service) and third order item (BI capabilities) and to detect the effects of BI capabilities on various CSCS aspects (namely vision and objectives, expectations and requirements, scope, involvement in supply chain, internal roles, responsibilities and objectives and communication). It was found out that BI capabilities affected the paths vision objectives, scope of operations, and internal roles and responsibilities positively and significantly.

BI capabilities related positively to the paths expectation, engagement, and objectives; however, the relationship was not as close as those of the other paths. Table 4 illustrates the acceptance of the following hypotheses:

H1(a). BI capabilities affect the vision and objectives of supply chain sustainability (vision) positively and significantly, H1 (d). BI capabilities affect the determination of the scope of activities (scope) positively and significantly, H1 (e). BI capabilities affect the assignment of internal roles and responsibilities (internal) positively and significantly, and H1 (b). On the other hand, these hypotheses were rejected: BI capabilities affect the establishment of supply chain expectations and requirements (expectation) positively and significantly, H1 (c). BI capabilities affect being engaged with suppliers and other businesses in the supply chain (engagement) positively and significantly and H1 (f). BI capabilities affect goal creation along with tracking and communication of performance (goals) positively and significantly. According to the structural model, BI capabilities affect the company's supply chain sustainability positively and significantly, with a path coefficient of 0.964 (p-value $<0.001$ ), which explains $90.1 \%$ of the variance. Therefore, there was strong support for the main hypothesis of the study given the significance of the path coefficient at $\mathrm{p}<0.001$. Totally, the $\mathrm{R}^{2}$ scores for the main variable (BIC: $90.1 \%$ ) whose explanation was provided by the research model were considerably large in line with the effect sizes for $\mathrm{R}^{2}$ described by Cohen (1988) and Chin (2010).

\section{Discussion}

\subsection{Key findings}

This research aimed to discover the association of BI and CSCS along with their various dimensions in analyzing verifiable and empirical data. The results strongly confirm that BI has a significant impact on the sustainability of the supply chain, however, it should be noted that the extent to which the chairpersons of the companies are familiar with the concept of sustainability and set their business policies towards sustainability is of paramount importance. BI will be useful as a strong tool and a valuable asset to developing a sustainable supply chain. The companies reach a better understanding of their jobs when raw data is received and analyzed by the BI system. As a result, it creates more productivity and creates a competitive environment with regard to other companies. This has a great impact on the growth and improvement of companies. By contrast, the companies that pay no attention to sustainability, if apply BI systems properly, they still approach sustainability unintentionally. Unfortunately, their impact on sustainable development is much less than those setting and prioritizing business policies with regard to sustainable development goals (SDGs). Although BI is generally useful in reaching a sustainable supply chain, the scope of the decision makers' knowledge about sustainability sciences and their commitment to SDGs is highly critical. Vision and objectives of the supply chain sustainability refer to the 
level of conception of sustainable supply chain development, and the scope of companies' commitment to grow the economy and meet the social and environmental objectives at the same time. As BI gathers data from the market to strengthen the strategic management of the company and adopt the right tactics in terms of production, distribution policies, branding, and promotion, it naturally provides a clear insight into the market. Accordingly, timely information about economic, social, and environmental aspects of sustainable development could be obtained from BI systems, indicating higher levels of vision. That is why the relationship between BI and vision is significant. However, decision makers' commitment to companies is a factor determining which BI has no direct impact. According to the findings and comparisons between industries, it was observed that industries producing goods such as food and medicine, as the essential goods, are more common on social networks such as Facebook, Instagram, and Twitter than industrial machinery industries. It was found out that data extraction from the pharmaceutical industry on Twitter was easier than on other social networks. In this regard, individuals on Twitter are more concerned with their shortcomings and needs, and it is easier to access data. On the other hand, it is difficult to extract data from Facebook because its source is closed and provides the data with difficulty. This issue comes true for the pharmaceutical industry; however, it may be different in other industries. According to the respondents' responses to the questionnaire, we inferred that social network provide us with an acceptable vision. Considering the pharmaceutical industry, we concluded that Twitter could provide us with more and better information than other social networks. Vision is accepted in this section since the companies use Twitter more than other social networks, and companies with stronger BI get more information from Twitter. To assess the effects of BI on the various sustainability dimensions such as scope, the companies must first have sufficient and comprehensive information about the BI system. When it comes to BI, we can examine the impact of its capabilities on the sustainability dimensions of the supply chain. The supply chains in different industries use BI differently. In a dynamic, customeroriented market, there is a need for smarter and faster methods. For example, the supply chains such as food and clothing, which are more essential for people, are more likely to show up on social networks than the other supply chains such as industrial machines. Given that the social networks provide us with the right vision, the experts have commented that social networks are formed and more highlighted based on the greater use of essential goods by individuals; hence, different supply chains must use their own BI model. Since there is now a lot of information in the ever-changing virtual networks, the process of analyzing the collected data needs to be performed more quickly and kept up-to-date, thereby leading to making the right decisions in a timely manner. For example, raw materials may become scarce one day but not the other day; hence, being informed and up-to-date plays an important role in making the right decisions. Given that this issue is also related to vision, and that the companies with timely and correct information have made more appropriate and immediate decisions under the existing conditions, vision is accepted and approved. The research results suggest that BI has a remarkable effect on the scope because the mangers make attempts to classify the markets and end-consumers based upon factors such as customer behavior, type of prescriptions issued by physicians across the county, competitors' strategic decisions, and local laws and orders. BI is used to collect the relevant data and prepare and analyze such data to provide valuable information as such the BI systems highly affect the scope of activities. As there is a wide range of products, and the market is highly large, from a logical viewpoint, one company cannot deal with all the issues. Thus, the mangers always spare their efforts to narrow up the activities within particular borders. BI determines which part of the market is more suitable to be involved and on which aspects of sustainability the company managers need to focus. For example, BI determines the type and number of drugs or supplements in 
demand in different regions as well as different types of consumers; therefore, the managers find out the exact amount of production and the right places to distribute what is included in the social dimension of sustainably. As a result, the production process becomes more efficient with much less waste, i.e. pro-environmental production. According to customer behaviors and habits, BI may suggest the best ways of promotion. Consequently, the costs of production, distribution, and promotion become reasonable and included in the goals of sustainable development. We identified three items as the main inputs to BI: the rules of the Food and Drug Administration (FDA), insurance laws, and medical guidelines, indicating the rationale behind the physicians' prescriptions. For example, regarding Coronavirus disease, which has long plagued the world, doctors have prescribed various medications to improve the disease. Some of these drugs are covered by insurance and some are not. Sometimes, patients select drugs with fewer effects on the disease since they are under the coverage of the insurance and make the patients pay less. Supply Chain Policies and BI analysis must comply with insurance laws. Government laws, insurance laws, and medical guidelines vary from country to country and region to region; hence, BI must be tailored to each region's needs. Because each country has its own culture and rules, it cannot be considered similar. Insurance companies need to consider these issues and create their own policies based on medical guidelines and supply chain strategies. To this end, they have to consider the whole supply chain. Because the Food and Drug Administration (FDA) passes laws and determines and influence the company's scope of activities, it is considered as the scope subset, according to the analysis of the responses provided by the pharmacologists. One of the aspects of BI capabilities is self-service, which emphasizes that the market information must be accessible for middle and senior managers to help them make the right decisions and adopt timely measures. In this case, the companies with a comprehensive BI system can make the production, distribution, branding, and promotion processes more efficient, resulting in more sustainable procedures. In this regard, the discussed mechanisms explaining the relationship between BI and scope need strong communication between the senior and junior managers inside companies, as provided by the BI self-service. Logically, the more the managers are in touch with each other using timely and high-quality information, the more they could take action for a sustainable supply chain. Studies have shown that the availability and timely use of data is an important challenge and makes us feel the need for building a BI system, especially a BI self-service since we can overcome this challenge using such a system. According to the results of the study, BI and Internal are significantly and positively associated. The technical features of BI systems improve communication and collaboration within an organization since sharing the existing knowledge leads to better decisions. The UN global compact encompasses four dimensions (namely human rights, labor, the environment, and anti-corruption), according to which 10 supply chain sustainability principles are derived. It should be mentioned that companies obtain legitimacy if they commit themselves to approach towards the UN global compact principles. In the literature, the social aspects of a sustainable supply chain (documented by UN global compact) such as human rights, labor, and corruption are receiving much less attention to economic and environmental aspects. In the BI systems, all the information is rapidly updated and easily accessible for mangers. Accordingly, the potential menace of corruption is removed because no one could censor or fabricate information; thus, all reports and financial transactions become systematically transparent. Some CSCS dimensions, which are not associated with BI significantly, show higher levels of relationships with business knowledge, strategies, planning, policies, and company annual budgets (investments) compared to BI infrastructure integration, BI functionality, and BI self-service. Moreover, the levels of understanding of sustainability and commitment to sustainable development goals are also considered. Several companies do 
not even know what sustainable development is, and some companies have not appreciated the magnitude of sustainability and thus feel no commitment in this regard. The relationships between BI with expectation, engagement, and goals were not strong but still positive. The establishment of the supply chain expectations as well as requirements (expect) means having a code of conduct or relevant contract language and inclusion of ethics or CSR (corporate societal responsibilities) clauses in a number of contracts with suppliers. the Expectation is highly dependent on the chairpersons' intention and commitment to sustainability, and since there is no governmental regulation or obligation across the country, many companies pay no attention to the magnitude of sustainability, even if they implement the BI systems. The relationship between BI and engagement was not significantly strong but still positive. In order to have contracts with partners to approach sustainability, some suitable partners, new partnership regulations, a novel system of decision making, and a new financial plan are required. Accordingly, the implementation of the BI systems is not enough. If an information sharing system is established between partners, and all the partners commit themselves to sustainability, and the other requirements such as financial programming are met, BI would be effective in developing a sustainable supply chain. Goal creation along with tracking and communication of performance-setting objectives are associated with supply chain policies and performance together with negotiations between stakeholders. The assessment of the most appropriate governance strategies and the continuous investigation of new chances to apply the BI systems in managing environmental, social, and economic effects could be costly and require coordinated and efficient support of the IT department. Moreover, some companies know the extent of their operations; however, they cannot set goals for their financial problems. In this case, BI could not be so effective if the companies encounter serious problems such as a financial crisis or a volatile management system that continuously changes the companies' budgets, policies, and plans because of economic fluctuations across the country. Various positions in a company, including suppliers, manufacturers, and distributors in the supply chain, are highly important, especially for the distribution companies since they are in direct contact with pharmacies and retailers. This case is related to one of the sustainability dimensions. According to the answers provided to us by the experts in the questionnaire and the interpretation of their responses, we found out that engagement was not accepted in this section since the broadcasting companies did not have the necessary cooperation and were corrupted and bribed, thus making them not to provide accurate and reliable information to retailers. Accordingly, this dimension was not accepted and rejected.

Insurance laws and medical guidelines, as a part of the BI inputs, must be coordinated, and the insurance rules must be in accordance with medical guidelines. For example, if a drug is harmful to pregnant women and causes abortions, it should not be prescribed for such women. And if the insurance company pays for that medicine, the medical guidelines should not be changed, and the insurance laws must comply with them to avoid problems. Furthermore, the policies in drug distribution companies and the sharing policies of drug distribution information must be in accordance with both medical guidelines and insurance laws. For example, in a children's hospital, medicines that are suitable for children should be distributed, and adult medicines are not suitable for this section. Or in a region where women are pregnant, safe and appropriate medications should be distributed to save the women. According to the respondents' analysis in the questionnaire, this section, as an engagement subset, was not approved due to the inconsistency of insurance laws and medical instructions.

Manufacturing companies, especially those operating in the pharmaceutical industry, need to continually improve their performance to survive in the competitive arena and also to become more effective. This performance is influenced by the environment where the company operates, and there is access to market information, competitors, and the environment 


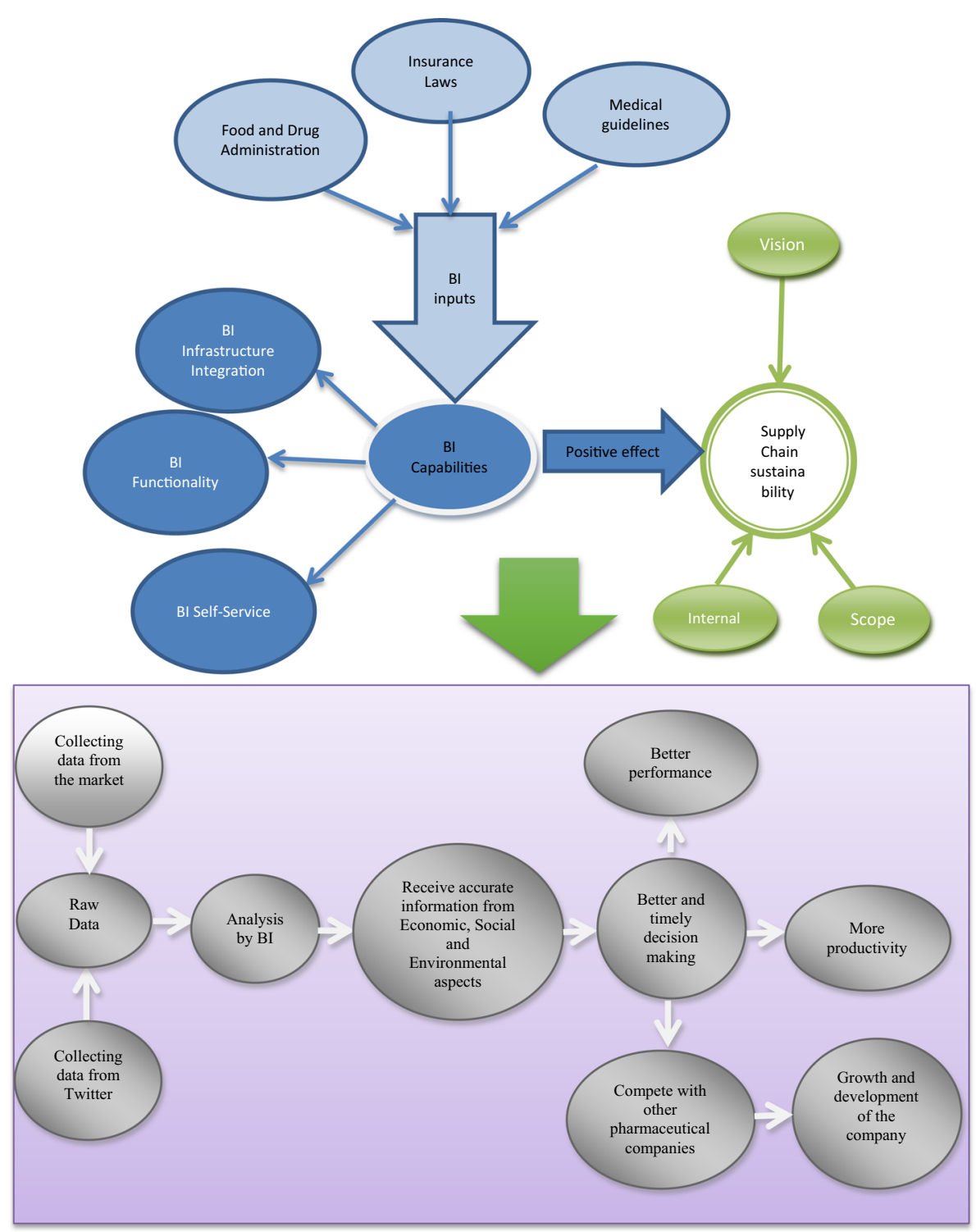

Fig. 4 Impact of BIC on different aspects

to evaluate performance and achieve goals. Those BI systems have access to the needed information at the right time. Many executives at pharmaceutical companies believe that the development of the BI systems was a costly process; hence, they did not consider BI to be useful and effective in improving performance. Because they believe the cost is greater than its profits, and that Iranian pharmaceutical companies are struggling with financial problems, they do not have enough money to build the BI system. They are not convinced that this is a necessity and look at it as a luxury item. For this reason, it is necessary to conduct research and identify the necessity of developing BI systems to be used in companies. Managers use 
the BI system to perform what they do and make more efficient and effective decisions. The BI system facilitates making sudden decisions. That is, if the smallest change occurs in the supply chain, it can be decided at any moment, thus persuading business executives to implement the BI system in their company (Fig. 4).

\subsection{Research implications}

The current study evaluated various aspects of supply chain sustainability and BI capabilities while examining the effects of BI capabilities on supply chain sustainability and its different aspects. Such capabilities have stronger effects on some of these dimensions. This article provides a new and better perspective on sustainable supply chain structures and BI using the UN supply chain sustainability questionnaire.

\subsubsection{Development of future research}

This research recommends future researchers to research some newer dimensions, find an objective criterion for this issue, and provide a practical solution to make the effects of BI on supply chain sustainability more operational. More specifically, it is also suggested to determine which subdivisions of BI affect what dimensions of supply chain sustainability, along with considering the type of company, public, or a private, to determine their differences in this regard. This article suggests researchers investigate the relationship between drug manufacturers and supplement manufacturers and explore how BI can affect drug manufacturers and complementary manufacturers. The researchers may also be interested in evaluating the use of BI for the sustainability of supply chain services. The respondents in this study with different positions in their companies responded to the questionnaire items differently. In this regard, their positions affected how they differently considered the methods of supplying the raw materials, the distribution of the goods, and the producer response method. The differences in the responses are the result of the features of positions in the supply chain; hence, the corporate positions (i.e., suppliers, producers, or distributors of goods) play a critical role in the supply chain. In other words, the distributors definitely have a response different from those of the manufacturers and suppliers because they are in contact with pharmacies and doctors. Researchers may be interested to research this topic in other industries. They can also check for differences in positions and examine which of the positions would be more effective at building a BI system to improve their performance. Future researchers can also test BI at the pharmacy level and detect how well the BI system can help pharmacies in making them useful.

Regional and national differences should also be of concern. Because there are different cultures and laws in different regions and countries having their own expression in cyberspace, understanding and interpreting such aspects is of great importance as well.

A comprehensive investigation is needed on the efficiency of supply chain sustainability regarding the covid-19 pandemic. New research approaches are required to speculate about how the strategies of distribution of Coronavirus vaccine and drugs affect the sustainability of the pharmaceutical supply chain. We also need to investigate the efficiency of supply chain sustainability in future studies. Furthermore, we can assess how business intelligence can help corporations and governments overcome the pandemic. 


\subsubsection{Modeling of uncertainty and dynamic}

In general, dynamic programming has received close attention (Azevedo et al., 2014). In addition, some researchers have placed emphasis on designing robust algorithms to deal with uncertain data using different uncertainty scenarios (Özmen et al., 2011(1), Özmen et al., 2011 (2)). In addition, some researchers have applied clustering techniques and regression models to identify various factors in the environment so that it is possible to analyze the corresponding optimization problems (Kropat et al., 2012a, 2012b, 2012c, Kropat \& Weber, 2009). Optimization problems are usually non-linearity and non-convex issues that some researchers offered a particular type of optimization, "Particle swarm optimization" to resolve this issue (Shabani et al., 2017). However, we do need continuous optimization and simultaneously various regression models to learn deeply about environmental factors (Kropat et al., 2012a, 2012b, 2012c). Furthermore, each system contains a number of multivariate states with is a critical factor, our model must be able to categorize these to strengthen the dynamic model as much as possible (Kropat et al., 2011). According to the previous studies, several academic articles have addressed the modeling of uncertainly and dynamics with topics such as reinforcing the network by dynamic models and decision support systems in an uncertain environment affected by items like natural disasters (Meyer-Nieberg et al., 2014). The concept of complicated regulatory systems dealing with uncertainty presents a format for the analysis in a circumstance that factors are difficult to predict. Clustering and classification, which are categorized as data mining methods, can be deployed to recognize the practically associated groups (Kropat et al., 2012a, 2012b, 2012c). However, modern applied mathematics is also offered to be used instead of some modeling (Kuter et al., 2014).

Since these essays have discussed the modeling of uncertainty and dynamics, it is deemed to be a highly important subject to be assessed in terms of the sustainable supply chain, especially in the pharmaceutical sector. This work inevitably encourages researchers to concentrate on the modeling of uncertainly and dynamics to improve the robustness of the pharmaceutical supply chain.

\subsection{Practical implications}

An organization must have a set of accurate and reliable data that is available at the appropriate level across all units. Different types of management decision makers can use this information. An examination of BI and BI self-services shows that there is a great demand for a BI system, and, as a competitive advantage for companies, it is still a hotbed of debate day (Stodder, 2015). The Chief Executive Officer (CEO) should know that it can influence the organization's BI capabilities; however, he cannot directly create this information and BI systems.

In 2010, the UN global compact made a group of UN global stakeholders and stakeholders work on supply chain sustainability. The group aimed to ensure that the business needs are met. The group was also to help businesses integrate UNGC into supply chain relationships and work groups (UN guideline, 2015). The UN General Assembly has more than 30 CEOs from different countries, and the UN annually reports the companies' progress with regard to the $10 \mathrm{UN}$ principles and help them achieve global goals (UN global compact, 2018). This article is interesting and useful for the UN managers because the UN questionnaire was adopted in this research, and its results were disseminated. This paper shows that BI can have positive effects on sustainability of supply chain, persuading the CEOs of the pharmaceutical companies to make huge investments in the implementation of the BI systems. This study reveals the real situation of BI and sustainable supply chain in Iran and represents 
some facts in the Iranian context as a developing country. Accordingly, this study may provide guidelines for executives and consultants dealing with BI and sustainable development. Companies need to have a system to create an integrated supply chain providing the users with precise, integrated, and organized information. In this article, it is concluded that supply chain managers understand the importance of BI and its effects on sustainability of supply chains. The findings would be beneficial to governments and pharmaceutical policy makers to provide the companies with mandatory or incentive laws to use BI for sustainability of supply chain and ask them to report the results continuously.

\subsection{Study limitations and suggestions for future works}

Even though the proposed model was tested using a standard questionnaire and reliable and valid data, there were several restrictions. The first restrictions of the study were associated with its focus on Iran, and future research in other countries can further clarify the links between BI capabilities and sustainable supply chains and provide more information in this regard. Second, cross-sectional data were used to test the model. It is recommended to re-test the model with the use of cross-sectional together with time series data to check its stability. In other words, the experts' responses should be rechecked since their views and circumstances may have changed. Third, there are various other dimensions of the supply chain, which may affect firm sustainability and decision making. For example, factors such as the company size, participants' position, product type, and culture and creativity in organizations can be examined in future research to detect how these factors make the supply chain more effective. This questionnaire was a self-report survey and based on personal opinions as such other methodologies should be considered in future research. One more limitation should be taken into account. In this study, outcomes depend on the static data structure (not dynamic). This could influence the final results of this research. It is important to mention that as we assessed 234 pharmaceutical companies and a large number of chief managers, it was virtually infeasible to design and assess objective criteria in all those companies. However, we agree that the final outcomes of this work are subjective which are not as valuable as objective measurements. Therefore, designing a study that analyses objective quantitative data for this topic is deemed necessary.

\section{Conclusion}

Given the high importance of supply chain sustainability and the need for BI systems in companies, a set of hypotheses was formulated based on the existing theoretical frameworks and literature. This paper aimed to investigate the relationship between BI and supply chain sustainability and the positive effects of BI on various dimensions of supply chain sustainability using the extensive examination of senior executives of Iranian pharmaceutical companies. In general, the findings showed that BI capabilities, including infrastructure integration, BI functionality, as well as BI self-service, have positive and strong effects on the sustainability of the pharmaceutical supply chain and its different aspects, consisting of vision, scope, and internal. This is a competitive advantage. The findings also showed a positive relationship between BI capabilities and other dimensions of supply chain sustainability such as expectation, engagement, and goals; however, they were not as strong as those of the other 
dimensions. If the board is to work on supply chain sustainability, the effects of BI capabilities on the company are greater. On the other hand, BI tools can also be used indirectly for supply chain sustainability.

It was concluded that BI could be an important factor in a sustainable reporting framework for health care providers and a powerful and valuable tool in developing supply chain sustainability. The findings would provide guidelines for top pharmaceutical managers and sustainable development professionals in Iran.

\section{Appendix}

The questionnaire

BI capabilities criteria

Please score from 1 (strongly disagree) to 5 (strongly agree) according to what is applicable to your organization

\begin{tabular}{|c|c|c|}
\hline Sub-dimensions & Indicators & Sources \\
\hline $\begin{array}{l}\text { BI reporting infrastructure } \\
\text { integration }\end{array}$ & $\begin{array}{l}\text { Our management reporting and } \\
\text { analysis systems (1 to 5): } \\
\text { - Are purely spreadsheet based (1) } \\
\text { vs. have a fully integrated IT } \\
\text { systems architecture (5); } \\
\text { - Consist solely of isolated and } \\
\text { individualized spreadsheets (1) vs. } \\
\text { are integrated by a common, } \\
\text { shared online platform and } \\
\text { database (5); } \\
\text { - Use highly manual processes to } \\
\text { extract data from transactional } \\
\text { systems (1) vs. have fully } \\
\text { automated integration with all } \\
\text { relevant transactional systems (5); } \\
\text { - Are based on data from disparate } \\
\text { spreadsheets (1) vs. source all data } \\
\text { from a single data warehouse (5) }\end{array}$ & $\begin{array}{l}\text { BI infrastructure integration } \\
\text { (References): Peters et al. } \\
\text { (2016), Keen, (1991), Mithas } \\
\text { et al. (2011), Chapman and } \\
\text { Kihn (2009), Rai et al. (2006) } \\
\text { Wetzels et al. (2009) }\end{array}$ \\
\hline $\begin{array}{l}\text { BI planning infrastructure } \\
\text { integration }\end{array}$ & $\begin{array}{l}\text { Our planning, budgeting, and } \\
\text { forecasting systems (1 to 5): } \\
\text { - Are purely spreadsheet based (1) } \\
\text { vs. have a fully integrated IT } \\
\text { systems architecture (5); } \\
\text { - Consist solely of isolated and } \\
\text { individualized spreadsheets (1) vs. } \\
\text { are integrated by a common, } \\
\text { shared online platform and } \\
\text { database (5); } \\
\text { - Use highly manual processes to } \\
\text { extract data from transactional } \\
\text { systems (1) vs. have fully } \\
\text { automated integration with all } \\
\text { relevant transactional systems (5); } \\
\text { - Are based on data from disparate } \\
\text { spreadsheets (1) vs. source all data } \\
\text { from a single data warehouse (5) }\end{array}$ & \\
\hline
\end{tabular}


BI capabilities criteria

Please score from 1 (strongly disagree) to 5 (strongly agree) according to what is applicable to your organization

\begin{tabular}{|c|c|c|}
\hline Sub-dimensions & Indicators & Sources \\
\hline BI reporting functionality & $\begin{array}{l}\text { Our management reporting and } \\
\text { analysis systems [strongly } \\
\text { disagree }(1) \text {; strongly agree (5)]: } \\
\text { - Have sophisticated formats and } \\
\text { presentation features; } \\
\text { - Have highly interactive reporting } \\
\text { features; } \\
\text { - Are very easy to use and navigate } \\
\text { by all users; } \\
\text { - Have rapid response and refresh } \\
\text { times }\end{array}$ & $\begin{array}{l}\text { BI functionality } \\
\text { References: Cheng et al. } \\
\text { (2020), Peters et al. (2016), } \\
\text { Ariav (1992), Wetzels et al. } \\
\text { (2009) }\end{array}$ \\
\hline BI planning functionality & $\begin{array}{l}\text { Our planning, budgeting, and } \\
\text { forecasting systems [strongly } \\
\text { disagree (1); strongly agree (5)]: } \\
\text { - Have rapid response and refresh } \\
\text { times; } \\
\text { - Are very quickly updated with } \\
\text { actual and base-level information; } \\
\text { - Allow forecasts and budgets to be } \\
\text { quickly created and revised; } \\
\text { - Allow sophisticated planning } \\
\text { models to be easily implemented } \\
\text { and changed }\end{array}$ & \\
\hline $\begin{array}{l}\text { management reporting and } \\
\text { analysis systems }\end{array}$ & $\begin{array}{l}\text { Dedicated analysts provide all the } \\
\text { information to middle managers } \\
\text { (1) to middle managers access and } \\
\text { interact } \\
\text { With the system(s) very frequently } \\
\text { (5); } \\
\text { - Dedicated analysts provide all the } \\
\text { information to senior managers } \\
\text { (1) to senior managers access and } \\
\text { interact } \\
\text { With the system(s) very frequently } \\
\text { (5) }\end{array}$ & $\begin{array}{l}\text { BI self-service } \\
\text { References: Johannes et al. } \\
\text { (2019), Lennerholt and Laere } \\
\text { (2019), Peters et al. (2016), } \\
\text { Dodson et al. (2008), Wetzels } \\
\text { et al. (2009) }\end{array}$ \\
\hline $\begin{array}{l}\text { planning budgeting and } \\
\text { forecasting systems }\end{array}$ & $\begin{array}{l}\text { Dedicated analysts provide all the } \\
\text { information to middle managers } \\
\text { (1) to middle managers access and } \\
\text { interact with the system(s) very } \\
\text { frequently (5); } \\
\text { - Dedicated analysts provide all the } \\
\text { information to senior managers } \\
\text { (1) to senior managers access and } \\
\text { interact with the system(s) very } \\
\text { frequently (5) }\end{array}$ & \\
\hline
\end{tabular}


Sustainability

Please share the result of on-line self-assessment on UN Global Compact website from 1 (No current action) to 5 (Best practices). http://supply-chain-self-assessment.unglobalcompact.org/start-yourassessment/

\begin{tabular}{lll}
\hline Dimensions & Sources & Score \\
\hline
\end{tabular}

Vision and objectives for supply chain sustainability

Establishing supply chain expectations and requirements

Determining Scope of Activities

Engaging with suppliers and other businesses in the supply chain

Assigning internal roles and responsibilities

Creating goals and tracking and communicating performance
Elkington (1994), Svensson and Wagner (2015), Wilson (2015), Dubey et al. (2016), Jeble and Dubey (2017), Devuyst et al. (2001), Gasparatos et al. (2008), Gibson et al. (2005), Ness et al. (2007), Pope (2006), Bond et al. (2012), Wu and Pagell (2011), Butner (2010), Christopher and Peck (2004)

Devuyst et al. (2001), Gasparatos et al. (2008), Gibson et al. (2005), Ness et al. (2007), Pope (2006), Bond et al. (2012), Wu and Pagell (2011), Butner (2010)

Devuyst et al. (2001), Gasparatos et al. (2008), Gibson et al. (2005), Ness et al. (2007), Pope (2006), Bond et al. (2012), Wu and Pagell (2011), Butner (2010), Dubey et al. (2016)

Barratt and Oke (2007), Jones et al. (2014), Gunasekaran et al. (2017), Devuyst et al. (2001), Gasparatos et al. (2008), Gibson et al. (2005), Ness et al. (2007), Pope (2006), Bond et al. (2012), Wu and Pagell (2011), Butner (2010), Kurniawan et al. (2017), Hatonen and Eriksson (2009), Malhotra (2014), Gunasekaran et al. (2017), Christopher and Lee (2004), Wu and Pagell (2011), Burns and Stalker (1961), Lawrence and Lorsch (1967), Kauffman et al. (2012), Dubey et al. (2016)

Burns and Stalker (1961), Lawrence and Lorsch (1967), Dubey et al. (2016), Devuyst et al. (2001), Gasparatos et al. (2008), Gibson et al. (2005), Ness et al. (2007), Pope (2006), Bond et al. (2012), Wu and Pagell (2011), Butner (2010)

Devuyst et al. (2001), Gasparatos et al. (2008), Gibson et al. (2005), Ness et al. (2007), Pope (2006), Bond et al. (2012), Wu and Pagell (2011), Butner (2010), Elkington (1994), Svensson and Wagner (2015), Wilson (2015), Dubey et al. (2016) 


\section{References}

Abdelzaher, D., Fernandez, W. D., \& Schneper, W. D. (2019). Legal rights, national culture and social networks: Exploring the uneven $\mathrm{T}$ adoption of united nations global compact. Journal of International Business Review, 28(1), 12-24. https://doi.org/10.1016/j.ibusrev.2018.05.001

Aliakbari Nouri, F., Shafiei Nikabadi, M., \& Olfat, L. (2018). Developing the framework of sustainable service supply chain balanced scorecard (SSSC BSC). International Journal of Productivity and Performance Management, 68(1), 148-170. https://doi.org/10.1108/IJPPM-04-2018-0149

Amirmokhtar Radi, S., \& Shokouhyar, S. (2021). Toward consumer perception of cellphones sustainability: A social media analytics. Sustainable Production and Consumption, 25, 217-233. https://doi.org/10.1016/ j.spc.2020.08.012.

Anderson, J. C., \& Gerbing, D. W. (1988). Structural equation modeling in practice: A review and recommended two-step approach. Psychological Bulletin, 103(3), 411-423. https://psycnet.apa.org/buy/198914190-001

Ariav, G. (1992). Information systems for managerial planning and control: A conceptual examination of their temporal structure. Journal of Management Information System, 9(2), 77-98.

Arnott, D., Lizama, F., \& Song, Y. (2017). Patterns of Business intelligence systems use in organizations. Journal of Decision Support Systems, 97, 58-68. https://doi.org/10.1016/j.dss.2017.03.005

Azevedo, N., Pinheiro, D., \& Weber, G. -W. (2014). Dynamic programming for a Markov-switching jump-diffusion. Journal of Computational and Applied Mathematics, 267, 1-19. https://doi.org/10.1016/j.cam. 2014.01.021

Bag, S., Gupta, S., \& Wood, L. (2020). Big data analytics in sustainable humanitarian supply chain: Barriers and their interactions. Journal of Annals of Operations Research. https://doi.org/10.1007/s10479-02003790-7

Bagozzi, R. P., \& Yi, Y. (1988). On the evaluation of structural equation models. Journal of the Academy of Marketing Science, 16(1), 74-94. https://doi.org/10.1007/BF02723327

Barratt, M., \& Oke, A. (2007). Antecedents of supply chain visibility in retail supply chains: A resource-based theory perspective. Journal of Operations Management, 25(6), 1217-1233.

Baruch, Y., \& Holtom, B. C. (2008). Survey response rate levels and trends in organizational research. Human Relations, 61(8), 1139-1160.

Bhargava, R. (2020). Role of management education in supporting sustainable development goals. Case Based Research, 68(1).

Bhattacharyya, G. K, \& Richard, A. J. (2010), Statistics: Principles and Methods by Bhattacharyya, Paperback, 6 th ed

Bond, A., Morrison-Saunders, A., \& Pope, J. (2012). Sustainability assessment: The state of the art. Impact Assessment and Project Appraisal, 30(1), 53-62. https://doi.org/10.1080/14615517.2012.661974.

Burns, T. E., \& Stalker, G. M. (1961). The management of innovation. London: Tavistock Publications. https:// worldcat.org/title/management-of-innovation/oclc/228964.

Butner, K. (2010). The smarter supply chain of the future. Strategy and Leadership, 38(1), 22-31. https://doi. org/10.1108/10878571011009859.

Caseiro, N., \& Coelho, A. (2018). Business Intelligence and competitiveness: The mediating role of entrepreneurial orientation. Competitiveness Review: An International Business Journal, 28(2), 213-226. https://doi.org/10.1108/CR-09-2016-0054

Chapman, C., \& Kihn, L. A. (2009). Information system integration, enabling control and performance. Accounting, Organizations and Society, 34(2), 151-169.

Cheng, C., Zhong, H., \& Cao, L. (2020). Facilitating speed of internationalization: The roles of business intelligence and organizational agility. Journal of Business Research, 110, 95-103. https://doi.org/10. 1016/j.jbusres.2020.01.003

Chin, W.W. (2010). Chapter 29: How to write up and report PLS analyses. In Wang, H. (Ed.). Handbook of Partial Least Squares. Springer, Berlin, Heidelberg, 655-690. https://doi.org/10.1007/978-3-540-328278_29

Chong, A. Y. L., Chan, F. T. S., Ooi, K. B., \& Sim, J. J. (2011). Can Malaysian firms improve organizational/ innovation performance via SCM? Industrial Management and Data Systems, 111(3), 410-431. https:// doi.org/10.1108/02635571111118288

Christopher, M., \& Lee, H. (2004). Mitigating supply chain risk through improved confidence. International Journal of Physical Distribution and Logistics Management, 34(5), 388-396. https://doi.org/10.1108/ 09600030410545436

Cohen, J. (1988). Statistical power analysis for the behavioral sciences. Routledge Academic, Beijing. www. scirp.org/(S(lz5mqp453edsnp55rrgjct55))/journal/Home.aspx?IssueID=9462 
Creswell, J.W. (2003). Research design: Qualitative, quantitative, and mixed methods approach, 2nd ed. Sage Publications, Thousand Oaks, CA. https://pdfs.semanticscholar.org/73b7/ 18e508fa943dfb22a9cb5fb17f888239ad0e.pdf

Devuyst, D., Hens, L., \& de Lannoy, W. (2001). How Green is the City? Sustainability Assessment and the Management of Urban Environments. New York, NY: Columbia University Press.

Dodson, G., Arnott, D., and Pervan, G. (2008). The use of business intelligence systems in Australia. The Australasian Conference on Information Systems Christchurch, New Zealand, ACIS 2008 Proceedings.

Dubey, R., Bryde, D. J., Foropon, C., Graham, G., Giannakis, M., \& Mishra, D. B. (2020). Agility in humanitarian supply chain: An organizational information processing perspective and relational view. Journal of Annals of Operations Research. https://doi.org/10.1007/s10479-020-03824-0

Dubey, R., Gunasekaran, A., Childe, S. J., \& Wamba, S. F., \& Papadopoulos, T. (2016). The impact of big data on world-class sustainable manufacturing. The International Journal of Advanced Manufacturing Technology, 84(1-4), 631-645. https://link.springer.com/article/10.1007/s00170-015-7674-1.

Elbashir, M. Z., Collier, P. A., \& Davern, M. J. (2008). Measuring the effects of business intelligence systems: The relationship between business process and organizational performance. International Journal of Accounting Information Systems, 9(3), 135-153.

Elbashir, M. Z., Collier, P. A., \& Sutton, S. G. (2011). The role of organizational absorptive capacity in strategic use of business intelligence to support integrated management control systems. The Accounting Review, $86(1), 155-184$.

Elkington, J. (1994). Towards the sustainable corporation: Win-win-win business strategies for sustainable development. California Management Review, 36(2), 90-100. https://doi.org/10.2307/41165746.

Ereth, J., \& Baars, H. (2020). A capability approach for designing business intelligence and analytics architectures. Conference Paper · January 2020. https://doi.org/10.24251/HICSS.2020.658.

Fulzele, V., \& Shankar, R. (2021). Performance measurement of sustainable freight transportation: Aconsensus model and FERA approach. Journal of Annals of Operations Research. https://doi.org/10.1007/s10479020-03876-2

Gasparatos, A., el-Haram, M., \& Horner, M. (2008). A critical review of reductionist approaches for assessing the progress towards sustainability. Environmental Impact Assessment Review, 28(4-5), 286-311. https:// doi.org/10.1016/j.eiar.2007.09.002.

Gibson, R., Hassan, S., Holtz, S., Tansey, J., \& Whitelaw, G. (2005). Sustainability Assessment - Criteria and Processes, Earthscan, London. https://www.taylorfrancis.com/books/9781849772716.

Gupta, M., \& George, J. F. (2016). Toward the development of a big data analytics, capability. Information and Management, 53(8), 1049-1064. https://doi.org/10.1016/j.im.2016.07.004

Gunasekaran, A., Papadopoulos, T., Dubey, R., Wamba, S. F., Childe, S. J., Hazen, B., \& Akter, S. (2017). Big data and predictive analytics for supply chain and organizational performance. Journal of Business Research, 70(January), 308-317. https://doi.org/10.1016/j.jbusres.2016.08.004.

Hair, J. F., Tatham, R. L., Anderson, R. E., \& Black, W. (2006). Multivariate data analysis, Pearson Prentice Hall. Bill Black, Louisiana State University, Baton Rouge, NJ. http://wiki.biomine.skelleftea.se/wiki/ images/3/37/Multivariate_data_analysis_wiki.doc

Hair, J. F., Jr., Howarda, M. C., \& Nitzl, C. (2020). Assessing measurement model quality in PLS-SEM using confirmatory composite analysis. Journal of Business Research., 109, 101-110. https://doi.org/10.1016/ j.jbusres.2019.11.069

Hatonen, J., \& Eriksson, T. (2009). 30+ years of research and practice of outsourcing-exploring the past and anticipating the future. Journal of International Management, 15(2), 142-155. https://doi.org/10.1016/ j.intman.2008.07.002.

Hussain, M., Khan, M., \& Ajmal, M. (2018). Exploration and assessment of the motivators of social sustainability in healthcare supply chains: Multistake holder's perspective. Sustainable Development, 27(4), 573-586. https://doi.org/10.1002/sd.1922

Jeble, S., \& Dubey, R. (2017). Impact of big data and predictive analytics capability on supply chain sustainability. The International Journal of Logistics Management, 29(2), 513-538. https://doi.org/10.1108/ IJLM-05-2017-0134

Johannes, W. H., Waal, V. D., \& Thijssens, T. (2019). Corporate involvement in sustainable development goals: Exploring the territory. Journal of Cleaner Production. https://doi.org/10.1016/j.jclepro.2019.119625

Jones, B. E., Squire, B., Autry, C. W., \& Petersen, K. J. (2014). A contingent resource-based perspective of supply chain resilience and robustness. Journal of Supply Chain Management, 50(3), 55-73. https://doi. org/10.1111/jscm.12050.

Katsaliaki, K., Galetsi, P., \& Kumar, S. (2021). Supply chain disruptions and resilience: A major review and future research agenda. Journal of Annals of Operations Research. https://doi.org/10.1007/s10479-02003912-1 
Kauffmann, L., Carter, C., \& Buhrmann, C. (2012). The impact of individual debiasing efforts on financial decision effectiveness in the supplier selection process. International Journal of Physical Distribution \& Logistics Management, 42(5), 411-433. https://doi.org/10.1108/09600031211246492.

Keen, P. G. W. (1991). Shaping the future: business design through information technology. Harvard Business School Press.

Koberg, E., \& Longoni, A. (2019). A systematic review of sustainable supply chain management in global supply chains. Journal of Cleaner Production, 207, 1084-1098. https://doi.org/10.1016/j.jclepro.2018. 10.033

Kropat, E., Weber, G.-W., \& Pedamallu, C. S. (2012). Regulatory networks under ellipsoidal uncertainty-data analysis and prediction by optimization theory and dynamical systems, Chapter 3, 27-56.

Kropat, E., Weber, G. W., \& Pedamallu, C. S. (2012). Regulatory networks under ellipsoidal uncertainty data analysis and prediction by optimization theory and dynamical systems. In: Holmes D.E., Jain L.C. (eds). Data Mining: Foundations and Intelligent Paradigms. Intelligent Systems Reference Library, vol 24. Springer, Berlin, Heidelberg. https://doi.org/10.1007/978-3-642-23241-1_3

Kropat, E., Weber, G. -W., Alparslan-Go“K. A. Z., and Özmena, A. (2012). Inverse problems in complex multimodal regulatory networks based on uncertain clustered data. In: Pinto A., Zilberman D. (eds) Modeling, Dynamics, Optimization and Bioeconomics I. Springer Proceedings in Mathematics \& Statistics, vol 73. Springer. https://doi.org/10.1007/978-3-319-04849-9_25

Kropat, E., \& Weber, G.-W. (2009). Robust regression analysis for gene-environment and Eco finance networks under polyhedral and ellipsoidal uncertainty. Journal of Optimization Methods and Software, 00(00), $1-16$.

Kropat, E., Weber, G. W., \& Belen, S. (2011). Dynamical gene-environment networks under ellipsoidal uncertainty - set-theoretic regression analysis based on ellipsoidal OR. Journal of Dynamics, Games and Science, 1, 545-571. https://doi.org/10.1007/978-3-642-11456-4_35

Kurniawan, R., Zailani, S. H., Iranmanesh, M., \& Rajagopal, P. (2017). The effects of vulnerability mitigation strategies on supply chain effectiveness: Risk culture as moderator. Supply Chain Management: An International Journal, 22(1), 1-15. https://doi.org/10.1108/SCM-12-2015-0482.

Kuter, S., Weber, G-W., Özmen, A., and Akyürek, Z. (2014). Modern applied mathematics for alternative modeling of the atmospheric effects on satellite images, Chapter 27.

Kwong, K., \& Wong, K. (2013). Partial least squares structural equation modeling (PLS-SEM) techniques using SmartPLS. Marketing Bulletin, 24(1), 166-199. www.scribd.com/document/266313116/PLSSEM-Techniques-Using-Smartpls

Lawrence, P. R., \& Lorsch, J. W. (1967). Differentiation and integration in complex organizations. Administrative Science Quarterly, 12(1), 1-47.

Lennerholt, C., \& Laere, K. V. (2019). Data access and data quality challenges of self-service business intelligence. The 51st Hawaii International Conference on System Sciences, 2018, 5055-5063. https://aisel. aisnet.org/ecis2019_rp/37

Liang, T.-P., \& Liu, Y.-H. (2018). Research landscape of business intelligence and big data analytics: A bibliometrics study. Journal of Expert Systems with Applications, 111, 2-10. https://doi.org/10.1016/j. eswa.2018.05.018

Lu, H. E., Potter, A., Rodrigues, V. S., \& Walker, H. (2018). Exploring sustainable supply chain management: A social network perspective. Supply Chain Management: An International Journal, 23(4), 257-277. https://doi.org/10.1108/SCM-11-2016-0408

Malhotra, S. (2014). Impact of outsourcing on the organisations opting for IT. International Journal of Marketing and Technology, 4(3), 115-122. hhttps://www.proquest.com/pqorigsite=gscholar\&cbl=1626341.

Melles, G. (2019). Views on education for sustainable development (ESD) among lecturers in UK MSc taught courses: Personal, institutional and disciplinary factors. International Journal of Sustainability in Higher Education, 20(1), 115-138. https://doi.org/10.1108/IJSHE-02-2018-0032

Meyer-Nieberg S., Kropat E., \& Weber P. D. (2014). Dynamical supply networks for crisis and disaster relief: Networks resilience and decision support in uncertain environments. In: Huisman D., Louwerse I., Wagelmans A. (eds) Operations Research Proceedings 2013, Operations Research Proceedings. https:// doi.org/10.1007/978-3-319-07001-8_42

Meyers, C. (2014). How data management and governance can enable successful self-service BI. BI Training Solutions: As Close as Your 19(4), 23 Logi Analytics, State of Self-Service BI Report.

Midya, S., Kumar Roy, S., \& Yu, V. F. (2020). Intuitionistic fuzzy multi-stage multi-objective fixed-charge solid transportation problem in a green supply chain. International Journal of Machine Learning and Cybernetics. https://doi.org/10.1007/s13042-020-01197-1

Mirzai, N., \& Seddigh, M. R. (2018). A randomized, double-blind, placebo-controlled trial of pentoxifylline augmentation of sertraline in treatment of drug-naive depressed women: A pilot study. 2nd International Congress on Biomedicine. ICB2018. https://www.icbcongress.com/2018/en/prp.php?o=1332\&st=A- 
Randomized,-Double-blind,-Placebo-controlled-Trial-of-Pentoxifylline-Augmentation-of-Sertralinein-Treatment-of-Drug-naive-Depressed-Women-A-Pilot-Study.

Mithas, S., Ramasubbu, N., \& Sambamurthy, V. (2011). How information management capability influences firm performance. MIS Quarterly, 35(1), 237-256.

Mizgier, K. J., Wagner, S. M., \& Holyst, J. A. (2012). Modeling defaults of companies in multi-stage supply chain networks. International Journal of Production Economics, 135(1), 14-23.

Montiel, I., Christmann, P., \& Zink, T. (2016). The effect of sustainability standard uncertainty on certification decisions of firms in emerging economies. Journal of Journal of Business Ethics. https://doi.org/10.1007/ s10551-016-3350-0

Muntean. M. (2018). Business intelligence issues for sustainability projects. Sustainability, 2, 335. https://doi. org/10.3390/su10020335.

Narayanan, A. E., Rajagopalan Sridharan, P. N., \& Kumar, R. (2018). Analyzing the interactions among barriers of sustainable supply chain management practices: A case study. Journal of Manufacturing Technology Management, 30(6), 937-971. https://doi.org/10.1108/JMTM-06-2017-0114

Ness, B., Urbel-Piirsalu, E., Anderberg, S., \& Olsson, L. (2007). Categorising tools for sustainability assessment. Ecological Economics, 60(3), 498-508. https://doi.org/10.1016/j.ecolecon.2006.07.023.

Özmen, A., Weber, G. W., Batmaz, I., \& Kropat, E. (2011). RCMARS: Robustification of CMARS with different scenarios under polyhedral uncertainty set. Journal of Commun Nonlinear Sci Numer Simulat, 16(12), 4780-4787. https://doi.org/10.1016/j.cnsns.2011.04.001

Peters, M. D., Wieder, B., \& Sutton, S. G. (2016). Business intelligence systems use in performance measurement capabilities: Implications for enhanced competitive advantage. International Journal of Accounting Information Systems, 21, 1-17. https://doi.org/10.1016/j.accinf.2016.03.001

Podsakoff, P. M., \& Organ, D. W. (1986). Self-reports in organizational research: Problems and prospects. Journal of Management, 12(4), 531-544.

Pope, J. (2006). What's so special about sustainability assessment? Journal of Environmental Assessment Policy and Management, 8(2), v-x. https://www.jstor.org/stable/pdf/enviassepolimana.8.3.v.pdf?seq=1\# page_scan_tab_contents.

Prajogo, D. I., \& McDermott, C. M. (2011). The relationship between multidimensional organizational culture and performance. International Journal of Operations and Production Management, 31(7), 712-735. https://doi.org/10.1108/01443571111144823

Rai, A., Patnayakuni, R., \& Seth, N. (2006). Firm performance impacts of digitally enabled supply chain integration capabilities. MIS Quarterly, 30(2), 225-246.

Rasche, A., (2020). The United Nations global compact and the sustainable development goals, pp. 228-241. https://doi.org/10.4337/9781788971966

Rodríguez, R., \& Svensson, G. (2018). Future direction of sustainable development in private hospitals: General similarities and specific differences. Journal of Business \& Industrial Marketing, 35(3), 537-550. https:// doi.org/10.1108/JBIM-12-2018-0399

Ross, S. M. (2004). Probability and Statistics for engineers and Scientists, Elsevier Science, 3rd ed

Rouhani, S., Ashrafi, A., Ravasan, A. Z., \& Afshari, S. (2016). The impact model of business intelligence on decision support and organizational benefits. Journal of Enterprise Information Management, 29(1), 19-50. https://doi.org/10.1108/JEIM-12-2014-0126

Samar Ali, S., Kaur, R., Persis, D. J., Saha, R., Pattusamy, M., \& Sreedharan, V. R. (2020). Developing a hybrid evaluation approach for the low carbon performance on sustainable manufacturing environment. Journal of Annals of Operations Research. https://doi.org/10.1007/s10479-020-03877-1

Sarstedt, M., Ringle, C. M., Cheah, J.-H., Ting, H., Moisescu, O. I., \& Radomir, L. (2019). Structural model robustness checks in PLS-SEM. Journals. Sagepub. https://doi.org/10.1177/1354816618823921

Saura, J. R., \& Bennett, D. R. (2019). A Three-stage method for data text mining: Using UGC. Business Intelligence Analysis. https://doi.org/10.3390/sym11040519

Shabani, M., Saberi Noghabi, A., \& Farshad, M. (2017). A new optimization formulation for determining the optimum reach setting of distance relay zones by probabilistic modeling of uncertainties. Journal for Control, Measurement, Electronics, Computing and Communications. https://doi.org/10.7305/ automatika.2017.12.1560

Shamsul, A., Bao, Y., \& Hoque, R. (2015). The impact of business intelligence on organization's effectiveness: An empirical study. Journal of Systems and Information Technology, 17(3), 263-285. https://doi.org/10. 1108/JSIT-09-2014-0067

Shokouhyar, S., Seddigh, M. R., \& Panahifar, F. (2019). Impact of big data analytics capabilities on supply chain sustainability. World Journal of Science, Technology and Sustainable Development, 17(1), 33-57. https://doi.org/10.1108/WJSTSD-06-2019-0031 
Shoukohyar, S., \& Seddigh, M. R. (2020). Uncovering the dark and bright sides of implementing collaborative forecasting throughout sustainable supply chains: An exploratory approach. Technological Forecasting and Social Change. https://doi.org/10.1016/j.techfore.2020.120059

Stodder D. (2015). Visual analytics for making smarter decisions faster - applying self-service business intelligence technologies to data-driven objectives. TDWI Best Practices Report

Sutrisno, A., Kumar, V., Handayani, D., Arief, R.K., Virdhian, S., and Punuhsingon ,C. (2019). Categorization of supply chain sustainability risks in SMEs: A Preliminary evidence from a developing country. Proceedings of the International Conference on Industrial Engineering and Operations Management Pilsen. Czech Republic, July 23-26, 2019.

Svensson, G., \& Wagner, B. (2015). Implementing and managing economic, social and environmental efforts of business sustainability: Propositions for measurement and structural models. Management of Environmental Quality: An International Journal, 26(2), 195-213. https://doi.org/10.1108/MEQ-09-20130099.

Tang, K. H. D., \& Al Qahtani, H. M. S. (2019). Sustainability of oil palm plantations in Malaysia. Journal of Environment, Development and Sustainability. https://doi.org/10.1007/s10668-019-00458-6,22,49995023

Tenenhaus, M., Vinzi, V. E., Chatelin, Y.-M., \& Lauro, C. (2005). PLS path modeling. Computational Statistics and Data Analysis, 48(1), 159-205. https://doi.org/10.1016/j.csda.2004.03.005

United Nations sustainable development summit (2015). https://sustainabledevelopmentun.org/post2015/ summit

United Nation guideline (2015). Supply chain sustainability, UN practical Guide for Continuous Improvement Second Edition. www.unglobalcompact.org/library/205. Accessed 6 Jan 2019.

United Nation global compact. (2018). Online quick self-assessment and learning tools. http://supply-chainself-assessment.unglobalcompact.org/start-your-assessment/. Accessed 6 Jan 2019.

Wamba, S. F., \& Gunasekaran, A. (2017). Big data analytics and firm performance: Effects of dynamic capabilities. Journal of Business Research, 70, 356-365. https://doi.org/10.1016/j.jbusres.2016.08.009

Wang, Y., \& Kung, L. (2018). Big data analytics: Understanding its capabilities and potential benefits for healthcare organizations. Technological Forecasting and Social Change, 126, 3-13. https://doi.org/10. 1016/j.techfore.2015.12.019

Wetzels, M., Odekerken-Schröder, G., \& Van Oppen, C. (2009). Using PLS path modeling for assessing hierarchial construct models: Guidelines and empirical illustration. MIS Quarterly, 33(1), 177-195.

Wilson, J. P. (2015). The triple bottom line: Undertaking an economic, social, and environmental retail sustainability strategy. International Journal of Retail and Distribution Management, 43(4/5), 432-447. https:// doi.org/10.1108/IJRDM-11-2013-0210.

Wonnacott, T. H., \& Wonnacott, R. J. (1990). Introductory statistics. Wiley

Wu, Z., \& Pagell, M. (2011). Balancing priorities: Decision-making in sustainable supply chain management. Journal of Operations Management, 29(6), 577-590. https://doi.org/10.1016/j.jom.2010.10.001.

Yeoh, W., \& Popovič, A. (2016). Extending the understanding of critical success factors for implementing business intelligence systems. Journal of the Association for Information Science and Technology., 67(1), 134-147.

Yilmaz, F., \& Tekin, R. N. (2018). Effects of early life factors on the health and quality of life of older adults. Journal of Psychogeriatrics. https://doi.org/10.1111/psyg.12278

Publisher's Note Springer Nature remains neutral with regard to jurisdictional claims in published maps and institutional affiliations. 